University of Louisville

ThinkIR: The University of Louisville's Institutional Repository

Electronic Theses and Dissertations

$12-2014$

\title{
Against the grain : the challenges of black discourse within intercollegiate policy debate.
}

Tiffany Yvonne Dillard-Knox

University of Louisville

Follow this and additional works at: https://ir.library.louisville.edu/etd

Part of the Educational Sociology Commons, and the Race, Ethnicity and Post-Colonial Studies Commons

\section{Recommended Citation}

Dillard-Knox, Tiffany Yvonne, "Against the grain : the challenges of black discourse within intercollegiate policy debate." (2014). Electronic Theses and Dissertations. Paper 2161.

https://doi.org/10.18297/etd/2161

This Master's Thesis is brought to you for free and open access by ThinkIR: The University of Louisville's Institutional Repository. It has been accepted for inclusion in Electronic Theses and Dissertations by an authorized administrator of ThinkIR: The University of Louisville's Institutional Repository. This title appears here courtesy of the author, who has retained all other copyrights. For more information, please contact thinkir@louisville.edu. 


\title{
AGAINST THE GRAIN: THE CHALLENGES OF BLACK DISCOURSE WITHIN INTERCOLLEGIATE POLICY DEBATE
}

\author{
By \\ Tiffany Yvonne Dillard-Knox \\ B.A., University of Louisville, 2001

\begin{abstract}
A Thesis
Submitted to the Faculty of the

College of Arts and Sciences of the University of Louisville

in Partial Fulfillment of the Requirements

for the Degree of
\end{abstract}

Master of Arts

Department of Pan-African Studies

University of Louisville

Louisville, Kentucky

December 2014 
Copyright 2014 by Tiffany Yvonne Dillard-Knox

All rights reserved 



\title{
AGAINST THE GRAIN: THE CHALLENGES OF BLACK DISCOURSE WITHIN INTERCOLLEGIATE POLICY DEBATE
}

\author{
By
}

Tiffany Yvonne Dillard-Knox

B.A., University of Louisville

A Thesis Approved on

June 16, 2014

by the following Thesis Committee:

Thesis Director, Dr. Joy Carew

Dr. Ricky Jones

Dr. Margaret D’Silva 


\section{DEDICATION}

I would like to dedicate my thesis to my family. For without their patience, support and encouragement, I would not have successfully completed this project.

To my parents, Larry and Dianne, you have always stressed the importance of education and hard work. I thank you for your continual encouragement and inspiration.

To my siblings, Lad, La Tica, Justine, and Ron, I appreciate the four of you being there for me whenever I needed help. Thank you for being a part of the village that it takes to raise a child. Thank you doesn't begin to express my gratitude.

To my husband, Corey, you are the best part-time single parent ever. Thank you for taking over the parenting, cooking, cleaning, and transportation during all of the times that I just had to keep writing. Without your support and patience, all of this would have been impossible.

To my son, Demetrius, you are the most selfless teenager I know. You never once complained about the time I spent on this thesis. You pushed me to do more. You encouraged me every step of the way. You even helped out around the house when needed. You are my superstar and I am forever grateful to have you.

Finally, I dedicate this thesis to the memory and spirit of Dr. J. Blaine Hudson. I made a promise to you that I intend to keep. 


\section{ACKNOWLEDGEMENTS}

I wish to thank my committee members for believing in me and helping me to develop as an academic, a writer, and a person. A special thanks to Dr. Joy Carew, my committee chair for the countless hours you spent reading, editing, discussing, learning

and being very patient throughout this entire process. Thank you to Dr. Ricky Jones and Dr. Margaret D’Silva for agreeing to serve on my committee. You are both two of my greatest mentors.

I would like to thank my University of Louisville "debate what" family, both past and present. You all are the most inspiring and dedicated group of people I know. Your perseverance and commitment to justice remind me of why I do what I do. I would like to acknowledge all of the Black debaters that came before me. What you accomplished and experienced will never be forgotten. 


\title{
ABSTRACT \\ AGAINST THE GRAIN: THE CHALLENGES OF BLACK DISCOURSE WITHIN INTERCOLLEGIATE POLICY DEBATE
}

\author{
Tiffany Y. Dillard-Knox
}

June 16, 2014

This research uses the speech community model of analysis to illustrate how language is used to determine inclusion into and exclusion from Debate. This has been done by examining the use of four Black discourse types in Intercollegiate Policy Debate: signifying, call and response, tonal semantics, and narrative sequencing to show the ways in which current debate practices (un)intentionally exclude Blacks. Upon examination, one can see that there is educational value to the methods used by majority of the Black student population within Debate. In addition to being a tool of empowerment for this student population, these students can also provide the overall Debate community with alternative perspectives and values. These can be useful to all students' development as active citizens within an increasingly diverse American society. This analysis could provide important insight into the next phase of the debate about Debate. 
TABLE OF CONTENTS

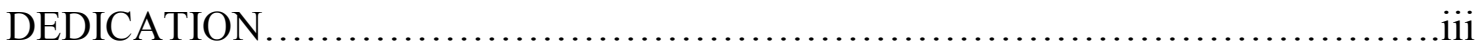

ACKNOWLEDGEMENTS .......................................................

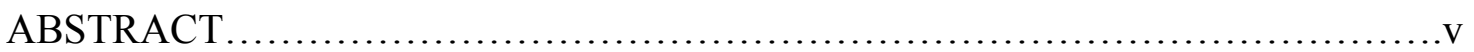

LIST OF TABLES........................................................vii

\section{CHAPTER}

1 CLASH OF CIVILIZATIONS: The Value of Language Differences..............1

2 DEBATE

Policy Debate Format........................................ 10

The Research Process............................................. 14

Traditional Versus Alternative......................................15

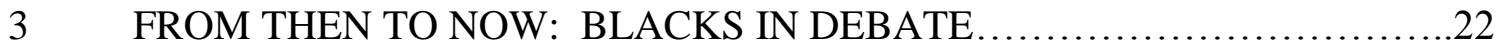

The Emergence of Urban Debate Leagues...........................28

Current State of Blacks in Intercollegiate Policy Debate................30

4 THE UNIVERSITY OF LOUIS VILLE MALCOLM X DEBATE

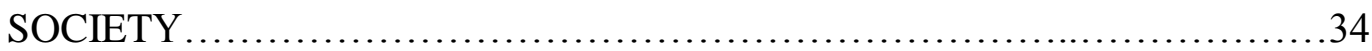

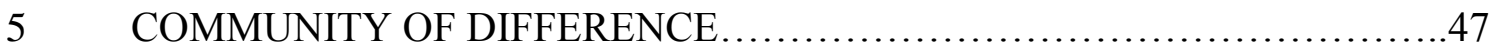

Debate as a Speech Community.................................47

African American English.......................................50

Black Discourse in Debate.....................................54

Norms: The Flow, Speed, and Line by Line Refutation.................55

Procedures: The Personalization of Debate and Topical Engagement...58

6 CONCLUSION AND DISCUSSION .................................. 71

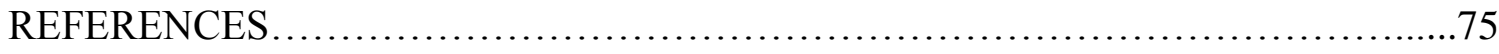

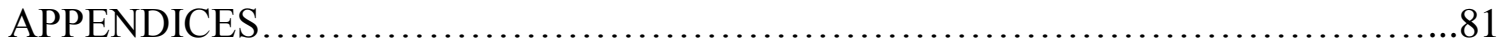

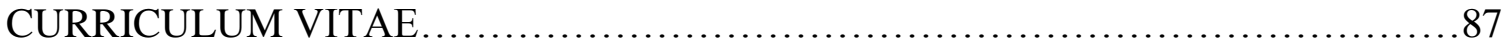


LIST OF TABLES

\section{TABLE}

A. Speech Order and Times................................................... 11 


\section{CHAPTER I}

\section{CLASH OF THE CIVILIZATIONS:}

The Value of Language Differences

Debate can be conceived as a speech community, one that has the potential to be a model for educational empowerment of minority populations. Yet, Intercollegiate Policy Debate organizations have failed to capitalize on this potential. In recent years there has been an influx of Black students entering the ranks of Intercollegiate Policy Debate. Most of these students entered the Debate community utilizing new methods of debate that are different from the traditional methods. These new methods are derived from a set of Black discourse practices, values, and perspectives. Unfortunately, most of the members of the Intercollegiate Policy Debate community are unwilling or underprepared to fully understand the functionalities of these new methods. Nevertheless, these methods can be invaluable to the empowerment of this student population, as well as, the Debate community at large.

Over the last few decades, there has been an increased focus on diversifying Debate in an effort to keep up with the levels of diversity on college campuses nationwide. However, there has been little consensus on what diversity means and how best to achieve it. The Debate community has focused on bringing in more students of color but the cultural environment of Debate is an important factor when considering how to best retain these populations. Therefore, there also needs to be an emphasis placed on ways to incorporate these new methods, values and perspectives. 
Debate is one of the most formidable academic activities in which students can be involved. It is an academic training ground for public speaking, literacy and research skills, and understanding the process of policy making. Debate prepares students to become active citizens in society long after their educational career has ended. Students who participate in Intercollegiate Policy Debate have access to an extensive network of society's more prominent leaders and Debate alumni, such as, politicians, attorneys, business executives, and university administrators. Debate has also produced seven former Presidents of the United States: Theodore Roosevelt, Woodrow Wilson, Franklin Roosevelt, John F. Kennedy, Lyndon B. Johnson, Richard Nixon, and Jimmy Carter. The skills acquired are invaluable to the long-term success of the students who participate in the activity.

In the early twentieth century Debate was a feature of colleges and universities across the nation, including Historically Black Colleges and Universities (HBCUs). According to John W. Parker (1955), Debate served as a "laboratory of democratic living," aiding students in the "process of developing scholars and citizens for movement in a democratic society (p. 146)." HBCUs competed amongst themselves initially, with the debate between Atlanta Baptist College (now Morehouse College) and Talladega College marking the first one of its kind (Brawley, 1917). However, they were eventually given the opportunity to debate against the white universities. Debates, in general, and the interracial debates, more specifically, were instrumental in training some of the most influential leaders of the Civil Rights movement. Leaders such as James Farmer, Jr. and Barbara Jordan, of Wiley College and Texas Southern University 
respectively, participated in Debate leagues. Black debaters became successful at one of the most prestigious academic competitions of the time: Debate.

In the mid-twentieth century Debate programs began to disappear in HBCUs and the level of black participation in Intercollegiate Debate dwindled to a few members here and there. These Black students attended predominantly white institutions. Debate returned to being an activity dominated by wealthy, white males. The decline of HBCUs' participation in Intercollegiate Policy Debate was partly due to the shift that occurred in 1947 from a single-day audience centered debate format to a multi-day tournament style debate format. Following this shift, debate competitions became more isolated from the larger public. Debate was becoming increasingly more competitive, more intense, and less accessible. This increased focus on competition became the driving force for the evolution of debate methods and techniques over the next few decades.

Currently Debate can be described as a high-speed, oral game of chess. It has become a game of information processing. Debaters now speak up to 400 words per minute and use highly specialized jargon as a way of communicating arguments and ideas. Under this model, persuasiveness is not only determined by one's oratory and research skills but also by one's ability to master the techniques of debate. Debate, to many, has become "just a game."

However, the role of debating for Blacks has always served dual functions. Blacks have participated in Debate recognizing the competitive, gaming aspects but debating has also served a social agenda for Blacks. Debate has often been used as a platform for disproving myths of intellectual inferiority. For some Black students, it has also been a way to escape the problems associated with living in the inner city. Students 
receive debating scholarships to college, the opportunity to travel nationally, a food stipend and many other benefits that they may have ordinarily not been able to access. To many Black debaters, Debate has been more than just a game-in a lot of cases, it has been a means for survival.

Unfortunately following the decline of HBCUs in Debate, the number of Black students participating in Intercollegiate Policy Debate also declined dramatically. There were two major events that occurred in an effort to rectify this problem. In 1985 Melissa Maxcy Wade, Director of Forensics at Emory University, started the Urban Debate Initiative in Atlanta, GA for high school students. This initiative grew into a national movement with high school Urban Debate Leagues (UDLs) developing in several urban centers throughout the country, including Baltimore, Chicago, and Washington, DC. The UDLs were largely populated by Black and Latino students. The program proved to be a successful tool for advancing academic achievement and increasing academic motivation for the student population that it served. Unfortunately, the number of Black and Latino students actually matriculating into intercollegiate debate was very small.

The second major event occurred in 2000 when Dr. Ede Warner, Director of Debate at the University of Louisville at the time, decided to shift the mission of the Debate program. As Warner stated in the University of Louisville Debate team's recruitment brochure in 2000, the mission was to increase "meaningful Black participation in Intercollegiate Policy Debate (University of Louisville Debate)." Warner began by changing the recruiting practices of the program to focus on bringing in more Black debaters. Eventually, the team began challenging the techniques and methods of Intercollegiate Policy Debate while developing new methods of engagement. These new 
methods included the use of Black oral traditions such as music, poetry, and narratives. Since that time, these new methods have been categorized and labeled "alternative" debate by members of the larger Debate community.

With the expansion of UDLs in conjunction with alternative debate methods, the Debate community has seen an increase in participation from Black students nationally. However, these changes also brought an increase in conflict over the value of these alternative methods. Utilizing alternative debate methods, the University of Louisville debate program reached heightened success in 2004 when the team of Latonia (Green) Craig and Elizabeth Jones became the first two African American women to earn the first and second overall speaker awards at the Cross Examination Debate Association's (CEDA) National Tournament. This success prompted two things: an increase in the number of alternative debate teams on the Intercollegiate Policy Debate circuit and motivated debate scholars to produce research regarding these alternative styles. Much of this new research included criticisms of the effects that alternative debate had on the larger Debate community. Joseph Zompetti (2004) criticized the methods used by arguing that using personal narratives in debates has led to an increasingly hostile Debate environment and has failed to achieve the goals of Debate set by the more traditional members of Debate, such as learning tolerance of difference. While other scholars (Atchison and Panetta, 2009) attributed the increase in hostility to the fact that students were challenging the Debate community's inability to increase diversity in actual debate competitions. They argued that these discussions should instead take place in a community forum as a better method for increasing diversity. 
These sentiments were shared by many members within the Debate community and this research became the foundational literature for the backlash that soon followed within the actual debate rounds. The debates between the alternative debaters and the traditionalists, or traditional debaters, have been referred to as the clash of civilizations. Since that time, the Debate community has been split along lines of stylistic choice with Traditional debate on one side and alternative debate on the other. At the heart of this debate about Debate has been the struggle over the value of difference: difference in styles, difference in perspectives, and difference in values.

One of the effects of this conflict is that the normative (traditional) practices of Debate have functioned as tools to maintain defacto segregation within the Debate community. If one were to attend a tournament one could see the segregated nature of the Debate community. Former national debate champion, Rashad Evans (2011) said this upon his return to the Debate community ten years following his debate career:

I attended this year's CEDA nationals and I must say that there was a huge difference in the makeup of the community at that tournament. There were definitely way more diverse faces in 2011 than there were in 2000 when I attended my first CEDA... That being said, the community definitely seems segregated, mostly by style of debate, but that segregation by style of debate has resulted in racial segregation as well. Debaters of color who have chosen nontraditional styles of debate are largely ghettoized in a corner and largely marginalized by the community (CEDA Forum).

While alternative debaters have achieved monumental levels of success, with each victory has come backlash from the Traditional debate community. For example, in 2013 Debate experienced the "uniting of the crowns" for the first time ever where two Black, openly gay males won both national titles in the same season while engaging in

\footnotetext{
${ }^{1}$ Uniting the crowns is a phrase used to describe win a team has won both the CEDA and NDT national championships in a single season.
} 
alternative debate methods. Following this triumph, there was a faction of traditionalists who attempted to secede from CEDA and form their own "policy only" debate league. Backlash has come from individuals, as well as, through structural barriers like the inequality that is inherent in the judge placement system, mutual preference judging

(MPJ). Acts like this are unacceptable for a community whose mission is to promote, encourage, and respect difference. The CEDA constitution (2014) states:

The mission of the Cross Examination Debate Association is to: create and support a community of scholar-advocates within the larger institution of higher education who respect one another as seekers of knowledge and agents of social justice; actively encourage participation in all forms of Academic Debate as a means to create personal leadership, transformation and growth; embrace a diversity of ideas and participants in order to foster an appreciation of the complexity and richness of human existence; promote the value of argumentative discourse as a means of producing reasoned, measured, cooperative solutions to contemporary problems of social and political significance (p. 3).

The failure to achieve this mission is an indication that more research is needed in an effort to create understanding of the value inherent in these alternative methods of debate for all who participate in Intercollegiate Policy Debate. A handful of scholars have already begun this process by theorizing about the productive nature of this new style of debate. These scholars have conducted research that offers detailed examinations of what these new methods are and how they are used to challenge the narrative and representations of Black youth within the larger socio-political context of Black academic achievement (Reid-Brinkley, 2008; Polson, 2012).

However none of the literature has yet to provide a linguistic analysis of the discourse patterns used by alternative debaters. Geneva Smitherman (1986), a leading linguist in African American English (AAE) research, has identified four major African 
American $^{2}$ discourse types: signifying, call and response, tonal semantics and narrative sequencing. This research will examine the use of these discourse types in Debate, as well as, the ways in which current debate practices (un)intentionally exclude the use of AAE. This research will add to previous discussions by providing new theories on debate that have yet to be explored. Thirdly, this research is particularly important to those who judge these debates but lack the necessary cultural competency to fully understand the complexities of this style of debate. Finally, these rich and complex discussions about language and behavior with regards to diversity in Debate make this research relevant to the literature on the value of the use of AAE in academic settings. An extensive discussion of Intercollegiate Policy Debate practices, the historical role of debate in Black America, and the current status of Blacks in Intercollegiate Policy Debate is a necessary prerequisite to examining the exclusion of the values, perspectives and use of AAE within the Intercollegiate Policy Debate community by Black debaters.

\footnotetext{
${ }^{2}$ For the purpose of staying true to the language of the linguistic literature on AAE, African American will also be used interchangeably with Black.
} 


\section{CHAPTER II}

\section{DEBATE}

Debate is one of the most relevant aspects of decision-making, both personal and societal. According to Freeley and Steinberg (2005), "debate is the process of inquiry and advocacy, a way of arriving at a reasoned judgment on a proposition (p. 6)." People use debate to decide the direction in which a company should go, whom to elect into political office, whether or not to enact a particular policy, and something as small as deciding what to eat for dinner. It can be an individual process or can be used as a tool of persuasion to convince others of a position.

There are many different formats of debate. They can be public debates such as the presidential debates or community forums. These debates are usually audience centered discussions around one or several topics. Debates also occur in an academic competitive format. Academic Debate formats include policy, Lincoln-Douglas, parliamentary, congressional, and public forum debates. Participation in Academic Debate provides students with a training ground for developing skills in critical thinking, critical listening, purposeful inquiry, prompt, analytical responses, problem-solving, and computer competencies. Additionally, Debate develops proficiency in reading and writing. The social values of Debate include courage, public speaking, social maturity, and multicultural sensitivities. While Debate in any form provides participants with various skills, the focus here will be on Academic Policy Debate. 
There are three major organizations for intercollegiate Academic Policy Debate in the United States; the Cross Examination Debate Association (CEDA), the National Debate Tournament (NDT), and the American Debate Association (ADA). Although they are distinct organizations with their own constitutions, there is substantial overlap in the format, norms and procedures across the three governing bodies. The differences in the three organizations are not very relevant to the following analysis of Academic Policy Debate. Therefore, Intercollegiate Policy Debate or Academic Debate will be used interchangeably to refer to college Policy Debate as one unit or community.

Intercollegiate Policy Debate has existed for decades. Policy Debate is an activity where two-person teams from various colleges and universities meet at different locations throughout the year to debate competitively over a given topic or proposition of policy. These competitions occur over a four day weekend, usually consisting of eight preliminary debates and four to five elimination debates. The preliminary debates happen where two, two-person teams debate in front of a single judge who decides a winner. After the preliminary debates, the teams with the best records go on to compete in a single elimination bracket with a panel of three to five judges, much like the NCAA tournament for college basketball. Each debate round lasts about two hours. The national organization ${ }^{3}$ has a topic selection process where a single proposition of policy is selected as the topic to debate throughout the entire season. For example, the topic for 2012-2013 was:

Resolved: The United States Federal Government should substantially reduce restrictions on and/or substantially increase financial incentives for energy production in the United States of one or more of the following: coal, crude oil,

\footnotetext{
${ }^{3}$ Although there are three governing bodies within intercollegiate policy debate, all three organizations adopt the same topic for debate each year.
} 
natural gas, nuclear power, solar power, wind power (Cross Examination Debate Association Wikipedia, 2014, para. 13).

The season typically lasts from September to April. The students prepare for these tournaments by conducting graduate level research around the selected topic and preparing policy briefs, several speeches and multiple argument strategies. Students must prepare arguments on both sides of this topic, affirmative and negative, because he/she will be required to debate each side equally at each tournament. This process of debating of both sides of the topic is called switch-side debate.

\section{Policy Debate Format}

Policy Debate is a very technical, high speed form of Academic Debate. There are diverse ways to approach Policy Debate. Traditional debate is the most common approach to Policy Debate and there are multiple variations that have grown out of or developed in opposition to Traditional debate. This section will begin by describing the standard structure of a debate.

A single debate round consists of a two-person team which is charged with affirming the given topic and a team responsible for negating that topic, as well as, a judge (or panel of judges) who decides the winner. During the debate each team gives two constructive speeches, two rebuttal speeches and has two cross examination periods. The speech order and times are in Table A. As can be seen, the negative has the opportunity to speak back to back with the $2 \mathrm{NC}$ (second negative constructive) and $1 \mathrm{NR}$ (first negative rebuttal). This is called "the negative block." The advantage of the negative block is countered by allowing the affirmative to speak first and last. 
Table A: SPEECH ORDER AND TIMES

\begin{tabular}{|l|l|}
\hline Speech & Length of Speech \\
\hline First Affirmative Constructive (1AC) & 9 minutes \\
\hline Cross Examination Period & 3 minutes \\
\hline First Negative Constructive (1NC) & 9 minutes \\
\hline Cross Examination Period & 3 minutes \\
\hline Second Affirmative Constructive (2AC) & 9 minutes \\
\hline Cross Examination Period & 3 minutes \\
\hline Second Negative Constructive (2NC) & 9 minutes \\
\hline Cross Examination Period & 3 minutes \\
\hline First Negative Rebuttal (1NR) & 6 minutes \\
\hline First Affirmative Rebuttal (1AR) & 6 minutes \\
\hline Second Negative Rebuttal (2NR) & 6 minutes \\
\hline Second Affirmative Rebuttal (2AR) & 6 minutes \\
\hline
\end{tabular}

*Each team is given a ten minute running clock for preparation time.

In a given tournament, there could be anywhere from sixteen to one hundred and fifty debates occurring at one time. The debate match ups-affirmative team, negative team, judge, location and start time of each debate—is disbursed on a schema called a pairing. Each team is identified by its school name and the first initial of each person's last name. For example, the team of Smith and Jones from the University of Louisville would appear on the pairing as, Louisville SJ. A sample pairing can be seen in Appendix I.

The affirmative (aff) starts the debate by presenting the case to affirm the topic. The on-case arguments or stock issues include: an explanation of a problem that exists in the status quo (inherency), reasons why the problem is harmful (harms), a specific plan of action to deal with the problem (plan), and explanation of how the plan solves the problem (solvency). The negative then counters with one or more argument strategies. They could refute one of the on-case positions, offer a counterplan, a kritik of underlying assumptions of the affirmative's position, and/or any disadvantages (disads) that could outweigh the benefits of doing the affirmative plan. Both teams discuss the impacts or 
the degree to which any of these things could create other effects. All participants, debaters and judges, track the arguments made in the debate on what is called a flow sheet (see Appendix II). The flow sheet is a written transcript of the debate, with the arguments presented in each speech recorded in vertical columns and linearly arranged so that a person can follow the flow of each argument as it evolves progressively through all the speeches in the debate. This is a skill that is very difficult to master without proper training and practice, primarily due to the rate of speed that is used to present arguments in a debate. The flow sheet serves two functions; 1) to process the debate and 2) to evaluate the debate. Freeley and Steinberg (2005) argue that all judges should have a comprehensive note-taking system so that he/she can record all of the significant developments during the debate in order to evaluate the debate effectively.

Once the final speech is given, the judge then renders a decision. While there is no particular standard or rubric for judging a debate, each judge does provide his/her own judging preferences in a judging philosophy (see Appendix III). Each debater has access to the judging philosophies prior to the debate. There are various types of judges, as indicated by their judging philosophy, across the Debate community. Freeley and Steinberg (2005) have identified seven types of judges in Academic Debate. The evaluator of argument is one that recognizes the inevitability of intervention, but strives to determine the quality of logic, clash, and evidence presented by debaters in order to choose the superior case or argumentative advocacy. The hypothesis-testing judge is one that focuses on testing the affirmative case and requires that the affirmative overcome any negative attack to win the decision. The issues judge is one that focuses on the stock issues and requires the affirmative to win all the stock issues to win the decision. The 
policymaker judge is one that contrasts the affirmative's and negative's policy systems and requires that the affirmative's policy system be viable and better than the negative's policy system in order to win the decision. This judge tends to evaluate competing policies on a basis of cost versus benefit. Skills judges focus on the skills listed on the American Forensics Association ballot—analysis, reasoning, evidence, organization, refutation, and delivery — and awards the decision to the team that has done the best debating with regard to these skills. The tabula rasa judge is the judge who takes no position and allows and expects the debaters to decide the theoretical framework for the decision. The final type of judge is the activist judge. With this approach the judge sees himself/herself as an active participant in the debate process. Activist judges believe debate is not a game, but an act. If no judging philosophy emerges in the debate, the judge may choose whatever judging philosophy seems most appropriate as a basis for the decision. This variation in judging becomes a major part of the debating activity, as the judge has the sole determining power of who wins and who loses. In addition to selecting a winner, the judge is also responsible for ranking the speakers one through four, with one being the best speaker, and assigning speaker points on a thirty point scale. While the scale ranges from zero to thirty, most judges tend to assign points from twentysix to thirty. The one to four scale ranks debaters in a single debate, while the thirty point scale is used to determine the rankings of all debaters participating in a tournament. All of this information is recorded on a ballot (see Appendix IV) and submitted to the tabroom. The tabroom is responsible for creating the pairings and tabulating the results of each debate. All of which is typically done using a computer software. The computer 
software is intended to minimize interference from tabroom workers in an effort to maximize fairness and transparency.

The process for selecting judges to evaluate each debate is called mutually preferred judging $(M P J)$. MPJ is a system where each team at the tournament ranks all of the judges electronically on what is called a preference sheet. There is not a standard rule for filling out the preference sheet. This process is entirely subjective, but there are some community norms that teams use, such as: ranking judges based on the average speaker points he/she has given in the past and ranking judges based on his/her debate philosophy. The ranking system at any given tournament varies. However, the most commonly used ranking system on the national collegiate circuit is ordinal ranking, whereas a ranking of one is considered "most preferred" and the last judge ranked is "least preferred." Additionally, judges are required to constrain themselves prior to the tournament. The rule of thumb on constraints is that judges should not judge teams that they are currently or have previously coached, nor should they judge debaters that they have a personal connection with. The judges are then placed by the tabroom in debates where they are mutually preferred.

\section{The Research Process}

The research process includes reading, researching, organizing, and filing information relevant to the position being taken. The articles usually come from Lexis Nexus, scholarly journals, etc. This information is then recorded on what is called a brief (see Appendix V). The brief includes the organizational information for filing purposes, the piece of evidence — verbatim quotes from the different authors (card) and 
the tag line (one-sentence summary of the card). The debaters should have a system on which to record (1) all information that may help in supporting their stand on the proposition and (2) all information that may be of help to opponents (Freeley and Steinberg, 2005). The research is then organized and filed in $t u b s$, plastic tubs used to carry evidence files. The more evidence tubs a team has, the more research he/she has acquired to use in any given debate. As a result, this research process is focused on finding the greatest amount of sources from the most highly revered expert in any given field to be analyzed in a very technical manner. Thus, Debate has become, according to debate theorist Roger Solt (2004), an activity that is "highly analytical" and "expert oriented" (p.43).

\section{Traditional Versus Alternative}

There are various approaches to Intercollegiate Policy Debate based on content preference and communicative style. These approaches are roughly categorized into two camps, traditional and non-traditional or alternative. The use of these terms is problematic for various reasons; however they are widely used and will be used here for the purpose of clarity.

In Traditional debate, speed is a huge strategic factor in the presentation of the speeches. During constructive speeches, and sometimes also in the rebuttals, debaters usually "talk fast - very, very fast - up to 400 words per minute" (Fine, 2001, p. 244). This is called spreading. Speaking at this rate is possible because debaters have practiced reading the pre-printed facts that consume the large amounts of evidence tubs prior to the tournaments. For debaters, "spreading serves a utilitarian function (Herder, 2004, p. 
87)." In other words, the goal of spreading is to be able to speak more words and, by extension, read more evidence cards in the time allowed than one's opponents. Fine further explains that, "Debate, for good or ill, is less concerned with rhetorical persuasion than with information processing" (p. 137). Students who can process more information in a shorter time stand a greater chance of winning. Therefore, the focus is on the quantity of evidence rather than the quality of the evidence. The following quote from Dr. Shanara Reid-Brinkley (2005) describes the method of organizing the progression of a Traditional debate:

Related to speed, is the practice of line by line debating, a practice by which debaters engage in the process of compartmentalizing and refuting one another's arguments. Debaters tend to provide some numerical or alphabetical outline structure by which he/she can easily reference arguments. Line by line debate requires students to respond to arguments presented by the opposing team by referencing specific arguments through whatever structure has been implemented by the speaker that initiated the argument. As a result of this extreme organization of arguments, debaters have developed a short-hand notational system by which he/she can record arguments in a debate round. This is the process of flowing or keeping a "flow" of the debate, a written record. It is not just debaters who flow, judges do, too. It is because the judges flow that it is critically important for debaters to be efficient at line by line debating. The judges refer to their flow in deciding debate rounds. They know if a team has not responded to an argument because it will not be recorded on their flow (of course there is room for notational error). Thus, it is critically important that debaters attend to specific arguments point by point (p. 104).

According to Tim Wise (2005), traditional debate has three functions. The first is to spread the other team so that they will "drop" —not respond to—one or more of your arguments. The second is to make sure that whatever the topic, the argument either for or against doing a certain thing in terms of public policy can in some way lead to nuclear war, ecological catastrophe, or worldwide economic collapse, no matter how absurd the linkage may be. The final function that Wise outlines is to "find the most obscure reference, source, or argument that you can find on a given subject, and no matter how 
"ridiculous" the argument, source, or reference, use that argument, source, or reference, because if it is obscure enough, the other team will not know how to respond (p. 32)."

A major concept that determines strategic decisions in any given debate is the notion of fiat and the idea of role playing. Fiat is a convention whereas debaters can assume a hypothetical implementation of a particular policy. This allows debaters to focus on whether a policy "should" be adopted and avoids discussions of whether it "would" be adopted. The purpose of fiat is to require the debaters to debate the merits of the proposition, and not the political machinations of how one might garner the votes necessary for enactment (Freeley and Steinberg, p. 71).

This notion of fiat is one place where alternative debate has broken from tradition in order to employ strategies that focused on in-round actions rather than a hypothetical implementation of a plan, or proposed policy action. The debaters were no longer limited to a hypothetical testing of policies that the United States Federal Government should or should not enact. Instead, the debaters began challenging the language and presentational choices made in debates. These debaters initiated challenges to traditional concepts regarding what constitutes valuable debate by incorporating music, drama and personal narrative.

Until recently, Debate was viewed primarily as an academic game (Snider, 1984). While there is value in the use of game simulation theory, this use of "gaming" as a way to view debating, allows one to speculate about the "what-ifs" of the future while ignoring the potential power in dealing with the right now. Components of alternative debate provide the tools necessary for acknowledging and proposing solutions for the problems of right now. Advocates of alternative debate see the activity as having the 
potential to be an educational tool of empowerment (Warner and Bruschke, 2001).

Participants, who engage in debates from an alternative standpoint, view themselves not only as players of a game, but agents of social change.

This change occurs in both form and content. In alternative debates, also known as performance debate, students will utilize what has come to be called a three-tier process. The three-tier process includes personal experience, organic intellectuals, and academic intellectuals. According to Nathan Abrams (1995), organic intellectuals have four characteristics. They must be a member of an "aggrieved community." As members of an aggrieved community, they should reflect the needs of that community. Thirdly, they attempt to challenge the power structures through the dissemination of subversive ideas. The final characteristic is that they strive to construct an "historical bloc"-a coalition of oppositional groups united around these subversive ideas. Academic intellectuals are academic experts in a particular field of research whose work is published in scholarly journals, non-fiction books, and other scholarly work, such as: theses, dissertations, and conference papers. Bartanen (1995) has described this type of knowledge as "authoritative evidence from an objective source." Elizabeth Jones of the University of Louisville described the function of the three-tier process as a method of validation:

A way in which you can validate our claims, is through the three-tier process. And we talk about personal experience, organic intellectuals, and academic intellectuals. Let me give you an analogy. If you place an elephant in the room and send in [sic] three blind folded people into the room, and each of them are touching a different part of the elephant. And they come back outside and you ask each different person they gone [sic] have a different idea about what they was [sic] talking about. But, if you let those people converse and bring those three 
different people together then you can achieve a greater truth (Reid-Brinkley, 2008, p. 84). ${ }^{4}$

This method of validation allows debaters to insert experiences and voices into debates that have traditionally been left out and/or marginalized. This concept comes from critical legal scholar Mari Matsuda's method of "looking to the bottom." Matsuda (1987) argues that, "those who have experienced discrimination speak with a special voice to which we should listen (p. 324)"

The presentation of argument in alternative debates can encompass the performance of rap music, poetry, metaphors and other art forms during a round (Polson, 2012). Freeley and Steinberg quote Jones' presentation of the following rap as a part of her affirmative case in favor of U.S. withdrawal from NATO:

Roma people feel just like me, tired of being deprived of their liberty. Relegated to ghettos, held as slaves, poor health care leading to early graves. Prison scars, from prison bars, walking round the prison yard.

No running water, no heat, no jobs, and everything you've seemed to love, you've lost.

While the rich get richer, who's paying the cost?

George Soros, Bill Clinton, to Dick Cheney, the so-called bearers of democracy.

NATO represents the military wing, of the all-powerful capitalist regime.

While you think gangsters listen to rap and sag,

They really wear suits and carry leather bags.

Politicians with the power to pick, define, and choose who will win and who will lose.

Not hearing the Roma or Palestine,

I guess it depends how genocide is defined (p.233)

\footnotetext{
${ }^{4}$ Alternative framework used by the University of Louisville and explanation of that framework as cited by Shanara Reid-Brinkley (2008), taken from a video of a debate speech given by Elizabeth Jones. Emory University Vs. University of Louisville, Double-Octa-Finals Ceda Nationals: Second Negative Rebuttal (Louisville, KY: 2004).

${ }^{5}$ Spoken word piece written by Elizabeth Jones as part of her 1AC.
} 
While this form of presentation is representative of a cultural art form, it is not limited to just art for art's sake. According to Polson, the use of musical and narrative forms in performance debate exemplifies a type of meta-information. An example of this can be seen in the excerpt above. Jones uses spoken word, not only as a performative piece, but also to describe the similarities of the relationship of some Blacks with American institutions to the relationship of the Roma people with NATO (North Atlantic Treaty Organization). These similarities are not connections that are easily recognized by outsiders of either subordinate group. Secondly, Jones plays on the word "gangsters." Instead of what people typically thinks of as a gangster, she applies it to politicians. The visual that she creates with her description of gangsters "wearing suits and carrying leather bags" as opposed to "listen(ing) to rap and sag(ging)," is part of the metainformation that Polson has articulated.

Polson goes on to say, "the form provides instruction to the listener about how to perceive and interpret the debate (p. 16)." The relationship that is created within Jones' spoken word piece, informs the judge that there are more ways to discuss justifying the United States Federal Government's "full withdrawal from NATO" than by any singular understanding of the topic, as framed by the authors of the topic paper. The topic in this particular season was

Resolved: The United States Federal Government should enact one or more of the following: Withdrawal of its World Trade Organization complaint against the European Union's restrictions on genetically modified foods; A substantial increase in its government-to-government economic and/or conflict prevention assistance to Turkey and/or Greece; Full withdrawal from the North Atlantic Treaty Organization; Removal of its barriers to and encouragement of substantial European Union and/or North Atlantic Treaty Organization participation in peacekeeping in Iraq and reconstruction in Iraq; Removal of its tactical nuclear weapons from Europe; Harmonization of its intellectual property law with the European Union in the area of human DNA sequences; Rescission of all or nearly 
all agriculture subsidy increases in the 2002 Farm Bill (Cross Examination Debate Association Wikipedia, 2014, para. 13).

This form is also used as a challenge to Traditional debate regarding what is acceptable evidence and style of delivery.

When these two opposing styles of Debate meet up in debate rounds, the community has termed these debates as clash of civilizations debates. The evolution of debate practices has progressed as a result of slow, minor changes that according to Roger Solt (2003) "were minor quarrels within an essentially unchallenged consensus" (p. 43). That is until 2000 when the University of Louisville, under the direction of Dr. Ede Warner, decided to voice major challenges to that general consensus.

The next section will explore the nature of Debate that created the need for those challenges. It will include a brief historical summary of the role of Debate within Historically Black Colleges and Universities (HBCUs), Malcolm X and Debate, the emergence of Urban Debate Leagues, as well as a look at the current status of Blacks in Intercollegiate Policy Debate. 


\section{CHAPTER III}

\section{FROM THEN TO NOW: BLACKS IN DEBATE}

College debate has existed in one form or another for over a century as an extracurricular activity on American college campuses, specifically at white institutions: Harvard, William and Mary, Yale, Princeton, Columbia, Pennsylvania, Brown, Rutgers, and Dartmouth. ${ }^{6}$ Over the course of time Debate evolved in its focus, moving from an emphasis on developing skills in formal logic as a method of proof to having literary and social agendas, in the form of literary and debating societies. Eventually, literary and debating societies were replaced by more formal and rigid forms of intercollegiate debating.

The first debate of its kind was held at Cambridge, Massachusetts in 1892 between Harvard University and Yale University (Parker, 1955). Recognizing its social and educational value of increasing literacy skills and informing social values, Debate began to proliferate across college campuses nationwide, including Historically Black Colleges and Universities (HBCUs). The first debate between two HBCUs was the contest between Atlanta Baptist College (now Morehouse College) and Talladega College in 1909 (Brawley, 1917).

\footnotetext{
${ }^{6}$ Also known as Colonial Chartered Colleges. Colonial Chartered Colleges are among the earliest universities in the United States.
} 
The format for Debate during this time was audience-centered. Debates were held in large auditoriums where patrons would pay to watch these intellectual match-ups. Teams usually had three persons. Two would debate each round; the third person would be the anchor man. He/she would know all of the arguments on both the negative and the affirmative (Beil, 2008). The debaters would need to be prepared to debate all of the topics on a slate of topics. The topic would then be agreed upon by the coaches of each team from that slate of topics and then a coin flip would decide sides. The governing forensics organization at the time was Pi Kappa Delta (PKD). Like everything else at the time, the governing body of forensic activity was segregated, initially based on a gentleman's agreement—a stated norm—and eventually outlined in the constitution ${ }^{7}$. Thus another Greek organization, Alpha Phi Omega, was created by Melvin Tolson, debate coach at Wiley College, to serve HBCUs.

The growth in Debate eventually led to the interracial debates, debates between HBCUs and the white universities, of the 1930s to the 1950s. These debates occurred during a very tumultuous time in American history. Jim Crow laws swept the South and the country was divided along racial lines, including educational institutions.

HBCUs were founded following the Emancipation Proclamation of 1863 in order to offer a formal education system to masses of newly freed Blacks. They were intended to uplift the Black community from the legacy of slavery by providing education that had been previously considered illegal for Blacks to obtain. According to Freeman and Cohen (2001) the objective of HBCUs has been to empower Black communitieseducationally, culturally, and economically. HBCUs have provided an environment that

\footnotetext{
${ }^{7}$ There is no longer a racial exclusion clause in the constitution. The PKD constitution currently upholds an anti-discrimination policy according to: http://www.pikappadelta.com/opsandorgstructure.html.
} 
fosters the knowledge and understanding of Black history and heritage and creates a sense of psychological well-being that enables Black students to take pride in their culture. These institutions prepared Black leaders to participate in the political economy of the South, in particular, and America, in general. Debate became one of the places that these new leaders began to emerge, such as: James Farmer, Jr., Barbara Jordan, and Thurgood Marshall to name a few.

James Farmer, Jr. eventually co-founded the Congress of Racial Equality (CORE) and became one of the prominent leaders of the Civil Rights Movement. Farmer started at Wiley College in Marshall, Texas as a precocious, fourteen year old freshman. In his autobiography, Lay Bare the Heart (1985), Farmer discusses the dualistic nature of being an academic in the South when he says, "Education merely made it harder for the brain to adapt to the demeaning things the system told it to do" (p. 121). Instead of adapting, Farmer used the skills and lessons taught to him by his debate coach, Melvin Tolson, to challenge the issues of segregation. Tolson once told Farmer:

My boy, it is customary for a professor to tell his students that the world is waiting for them with open arms. Well, that's a lie. There are men waiting for you, all right—with a big stick. Learn how to duck, and counterpunch (p. 121).

Debate became the method by which he learned to "duck and counterpunch." $\mathrm{He}$ engaged in debates with whites at the National Conference of Methodist Youth over the motion to call on Congress to pass a federal anti-lynching bill. He also travelled across the country engaging in interracial debates while touring with the Wiley debate team. Debate afforded him the opportunity to "rub shoulders with some of the brightest young men and women in America" (p. 129). 
Debate was also utilized by many other prominent Blacks in similar fashions.

Barbara Jordan, the first Black elected to the Texas Senate after Reconstruction, was a National Debate Champion at Texas Southern University. Her coach, Tom Freeman was quoted in Barbara Jordan: A Self Portrait (1979) as saying:

I'd take students around the country in order to let them practice the normal skills and competencies against such schools as Chicago and Boston [predominately white institutions]. I wanted them to hold their own. I wanted them to learn to think (p. 77).

Supreme Court Justice, Thurgood Marshall, was also a very successful debater. He debated while attending Lincoln University in Philadelphia, Pennsylvania. Marshall's debate experience provided him with the skills to successfully "engineer the litigation and persuade the Court to unanimously proclaim the principles announced in Brown v. Board of Education, the 1954 school desegregation cases (Barker, Jones, and Tate, 1999, p. 160)."

College was not the only place that trained Blacks to become great orators with the capacity to persuade audiences to their point of view. During a period from the 1930s to the 1950s, educational reform was taking place in American prisons. It had been decided that learned criminal behavior could be unlearned. As part of the prison reform movement, formal speech and debate activities were introduced to some of the American prisons.

Perhaps one of the most well-known Black debaters was Malcolm $\mathrm{X}^{8}$. Malcolm $\mathrm{X}$ was introduced to debate while a prisoner at the Norfolk [Massachusetts] Prison

\footnotetext{
${ }^{8}$ The University of Louisville's debate program eventually changed the name of the program in an effort to pay homage to the legacy of Malcolm X's debating experience. The program is now called The University of Louisville Malcolm X Debate Society.
} 
Colony. In The Autobiography of Malcolm X (Malcolm X and Haley, 1965), he

described his debating experience by stating:

I've told how debating was a weekly event there at the Norfolk Prison Colony. My reading had my mind like steam under pressure. Some way, I had to start telling the white man about himself to his face. I decided I could do this by putting my name down to debate. Standing up and speaking before an audience was a thing that throughout my previous life never would have crossed my mind. Out there in the streets, hustling, pushing dope, and robbing, I could have had the dreams from a pound of hashish and I'd never have dreamed anything so wild as that one day I would speak in coliseums and arenas, at the greatest American universities, and on radio and television programs, not to mention speaking all over Egypt and Africa and in England. But I will tell you that, right there, in the prison, debating, speaking to a crowd, was as exhilarating to me as the discovery of knowledge through reading had been. Standing up there, the faces looking up at me, things in my head coming out of my mouth, while my brain searched for the next best thing to follow what I was saying, and if I could sway them to my side by handling it right, then I had won the debate -- once my feet got wet, I was gone on debating (p. 184).

The weekly Norfolk debates attracted large audiences that included most of the prisoners, visitors, and representatives of organizations connected to the topic under discussion (Branham, 1995, p. 121). According to Branham, "the Norfolk debate program provided Malcolm X with a new medium for the expression of his emerging political philosophy and with a regular forum in which he could both appeal to fellow prisoners and confront white adversaries (p. 121).”

Blacks used Debate to hone their intellectual skills and as a platform to publicly challenge issues of social injustice. These debaters challenged the oppression occurring in a segregated legal system, as well as, the perceptions of inferiority of Black intellectualism. There was an unspoken criterion to engage debates just like the students of predominately white institutions to prove that there was no difference in the intellectual capabilities of Blacks. They achieved this by presenting themselves in a similar fashion to whites in the way that they spoke, dressed, and their mannerisms. The 
debaters used the given topic as a spring board to challenge the ideologies of America and American institutions and offer an alternative view of the world.

HBCUs competed in interracial Academic Debates for nearly three decades with these objectives at the heart of competition. Tolson believed the interracial debates to be "a breakthrough in the troubled race relations of the country" (Beil, 2008, para. 24). He went on to say:

When the finest intellects of Black youth and white youth meet, the thinking person gets the thrill of seeing beyond the racial phenomena the identity of worthy qualities...In the South I have seen ex-slaves shaking hands with the grandsons of the masters after the debate (para. 24).

Jarrett Hobart, former Wiley debater, agreed that the interracial debates were valuable to race relations in America. Hobart believes that these debates led to changes in perceptions of Black intellect. He was quoted as saying, "I know several instances personally in which white coaches and debaters of white universities have admitted the superiority of certain Negro debate teams (Beil, 2008, para. 25).”

With the proliferation of debate formats, these valuable match-ups between the elite white universities and HBCUs began to disappear. In 1947 the United States Military Academy (West Point) hosted the first National Invitational Tournament. This became the predominant format for hosting Policy Debate tournaments and the format that exists today. This format came under much criticism from directors and coaches of HBCUs. The critics contended that shifting from a single, audience centered debate format to a weekend long tournament format with several debates occurring simultaneously, meant that too many debates were crammed into a single evening over the duration of that weekend. As a result, the format discouraged attendance from the public and audiences became non-existent. There was also dislike of the employment of 
the same topic nationally. There was no longer a slate of topics to choose from, minimizing the number of issues being addressed to just one per season (Parker, 1955). The emphasis on competition began to overshadow the initial importance of Debate for HBCUs. With the disappearance of large audiences, the activity became isolated from the members of academia who did not participate in Debate, as well as, other members of the community. At the turn of the new millennium ${ }^{9}$, HBCUs remain inactive in Intercollegiate Policy Debate but can be found participating in other formats of debate such as speech events and public forum debate. Intercollegiate Policy Debate tournaments have become comprised of mostly rich, white males. It is important to note that the style of debate engaged during this time was more oratory in nature and less technical, unlike the current form of debate as described in Chapter Two.

\section{The Emergence of Urban Debate Leagues}

Since the interracial debates of the 1950s there has been a void in the presence of Black debaters in intercollegiate debate. There were a few, relatively successful Black debaters on the college circuit, however, the existence of Blacks in Debate was small relative to the total population of Policy Debaters. The next big shift towards diversity in Debate came at the high school level with the emergence of Urban Debate Leagues (UDLs).

The urban debate initiative was started in 1985 by Melissa Maxcy Wade, Director of Forensics at Emory University, in partnership with the Atlanta Public School System. Two key figures in this process were Dr. Larry Moss (Therrell High School, Atlanta) and

\footnotetext{
${ }^{9}$ According to records from the West Point Debate Council and Forum, Howard University is the only HBCU that participated in the West Point (US Military Academy) Tournament. Howard University also attempted to resurface in intercollegiate policy debate in the early 2000s but only lasted a year or two.
} 
Betty Jessie Maddox (Harper High School, Atlanta). The Barkley Forum at Emory University received a grant from the Phillips Petroleum Company and the National Forensics League to bring Policy Debate to the Atlanta public schools. It started as part of the educational reform movement in an effort to correct the problems associated with low academic achievement of underrepresented groups. According to Reid-Brinkley (2008), Wade sent her nationally ranked debaters to volunteer coach at Atlanta city schools. Most, if not all, of these volunteer coaches participated in the traditional forms of debate - the highly technical, jargon laden methods of debate. Therefore, the Urban Debate League students were also trained in Traditional debate.

The Atlanta initiative was successful and became a model for urban debate across the nation. Philanthropist George Soros and the Open Society Institute (OSI) became a funding partner and a national organization, the Urban Debate Network, was eventually formed. In 2002, the National Association for Urban Debate Leagues (NAUDL) took over the national leadership. There are currently UDLs in nineteen cities across the United States with more than 7,000 students that have competed (NAUDL, 2014).

The purpose of the Urban Debate Leagues is to use debate to motivate students and, by doing so, increase academic achievement, provide a bridge to college, and develop leaders. According to the NAUDL website, Urban Debate Leagues have proven to increase grade-point averages, improve graduation rates for students at risk of dropping out, and to improve college matriculation rates. Urban Debate is offered to school systems that are "eighty-six percent people of color" and "seventy-six percent are from low-income families (NAUDL, 2014).” Debate educators (Lee, 1998; Warner and Bruschke, 2001) have argued that the Urban Debate Leagues provide a space for 
empowerment for disenfranchised individuals. Ed Lee, former UDL participant and current Director of Debate at Emory University has gone as far as to state that Debate provides its students with a "homeplace." Lee contended that school did not offer him a place of empowerment that would train him in the skills needed to speak out against the oppression that he experienced on a daily basis. However, his experience in the Atlanta UDL provided an intellectual safe space for him. He argued that Debate "provides students with a pedagogical tool that simultaneously opens the mind to alternatives and empowers students to take control of their own lives (p. 95)."

The overall impression is that the movement to bring Debate to underrepresented groups has been a successful one. This can be observed by the positive attention given by the media ${ }^{10}$, as well as, the remarks by the former First Lady Laura Bush who stated, "Debate is a healthier alternative than violence and gangs. It helps students identify a good argument and reject bad ones, and it makes them better able to deal with negative peer pressure." However, with the success of the Urban Debate initiative, the question remained, why were these students not actually matriculating into the ranks of Intercollegiate Policy Debate at greater rates? This could be due to recruitment bias, students choosing to attend colleges without debate programs, or the cultural environment that exists within Intercollegiate Policy Debate is not welcoming. Further research would need to be done in order to understand the relationship between the success of UDLs and the lack of diverse bodies within Intercollegiate Policy Debate. Nevertheless, the next section will explore the contemporary issues associated with diversity and Debate at the collegiate level.

\footnotetext{
${ }^{10}$ There have been human interest stories done on UDLs in The New York Times, Newsweek, and on CBS' "60 Minutes."
} 
The Current State of Blacks in Intercollegiate Policy Debate

In an examination of Black participation in CEDA Debate by Peter Loge (1991) a survey was sent out to the Fall 1989 CEDA mailing list in an attempt to assess the participation of Blacks in Debate. The study found that only $3.69 \%{ }^{11}$ (25 out of a total of 677) of the debaters at predominately white institutions were black. Of that percentage, less than one percent was deemed competitively successful, where competitive success was defined as participation in late elimination rounds at large tournaments.

The Commission on Women and Minorities, a committee charged with increasing the number of women and minorities in CEDA, began developing a demographic questionnaire in 1991 asking for gender and race of all directors, coaches, and competitors. All schools participating in the national CEDA tournament were asked to complete the questionnaire. The data, over the course of five years (1991-1995), included: "390 directors of debate, 421 coaches of debate, and 1,943 debate competitors (p. 177)." Debate theorist Pamela Stepp (1997) compiled the data and found that, during this time, there was an increase in minority male directors, decrease in minority female directors, decrease in minority male coaches, more minority female coaches than directors, and an increase in overall minority participation of competitors. The total average participation for minority debaters during this time was $13 \%$. However, the study acknowledged that the increase is far from representative of the number of minorities at American colleges and universities. Unfortunately, Stepp's research does not separate the races. They are grouped together into a category called minorities.

\footnotetext{
${ }^{11}$ Texas Southern University was also a respondent of the survey but is not included in this number because it is an HBCU.
} 
Stepp, along with Beth Gardner (2001) conducted a similar analysis of Stepp's 1997 study to examine the participation of women and minorities at the national CEDA debate tournament over the course of a decade, 1991-2000. They found that minority directors increased from $1 \%$ to $11 \%$. They noted that this increase was due almost entirely to the increase in minority male directors. There was also a statistically significant increase in minority coaches. Finally, the percentage of minority debaters increased from $11 \%$ to $15 \%$. Again, while these numbers have been on the rise, they are still lower than the percentage of minorities that make up the minority population at colleges and universities, 55.8\% women and 26.2\% minorities (Nation, 1999). Regrettably, this research also does not specifically define minorities.

While the data has revealed a lot about the issue of diversity in Debate, it is important to note that most of the demographic studies do not offer specifics in terms of Black participation in Debate. Aside from Loge's analysis, the other studies group all people of color in a category called minorities. Loge has done the most comprehensive analysis of Black participation in Intercollegiate Policy Debate. However, that study is over two decades old and updated numbers would be useful in assessing how far the community has come with regards to Black participation in Debate.

The above studies also identify barriers to participation for women and minorities in Intercollegiate Policy Debate. Loge (1991) identified several barriers to participation for Black students: attitudinal, the need to assimilate, the lack of knowledge about the activity in Black communities, the "whiteness" of the activity, the time commitment, and the lack of relevance to the lives of Blacks (p. 83). Other barriers that have been acknowledged are: perceptions of judge bias, novice recidivism, lack of representation in 
coaching ranks, topic selection, perceptions of racism, and the inherent competitive structures (Logue, 1987; Stepp, 1997; Rogers, 1997).

Several solutions have been offered and strategies to increase diversity have been implemented, such as: promoting awareness and outreach with the emergence of Urban Debate Leagues, the implementation of a sexual harassment policy, the creation of the Commission of Women and Minorities, and diversity forums at national tournaments. These new strategies have provided hope to women in the community but have done very little to change the status of Blacks in Debate. There was no creation of a racial harassment policy, no Black Caucus created, and the students from the UDLs were not matriculating into Intercollegiate Policy Debate in large numbers. The next chapter will examine the emergence of the University of Louisville Malcolm X Debate Society. 


\section{CHAPTER IV \\ THE UNIVERSITY OF LOUISVILLE MALCOLM X DEBATE SOCIETY}

The Beginning

The University of Louisville has had an active debate team since the late 1970s. The demographics of the team consisted of mostly white males, with a handful of females and Black students, over the course of the thirty years following its inception. During this time, the team competed in the Traditional debate norms and procedures and was very successful, even winning the National Debate Tournament in 1982. Dr. Ede Warner, a former debater himself, took over as Director of the program in the mid-1990s and continued in its tradition. Warner would recruit from the national high school circuit and coach debate in the traditional style of debate, following in the traditions of the previous Directors of Debate.

In the 1999-2000 season the team consisted of two white males, two white females and two African American females, one of whom he recruited from the New York Urban Debate League. The debaters were coached to run racially specific arguments with an emphasis on the Black perspective. Warner believed these arguments to be strategically advantageous because they were "true." Also during this time, Warner (2000) wrote an article entitled, "A Vision for the Future", where he made arguments for increasing the diversity of the community. He stated: 
The art of recruiting is a final challenge for the new millennium; and not just recruiting talented debaters, but attracting a diversity [sic] woefully lacking in the participation levels of collegiate debate. Improving the numbers of women and people of color cannot solely be measured just in terms of debate participation, although that is a starting point. We must also develop and cultivate numbers in the graduate assistant ranks, the coaching ranks, and alumni of the "long gray line" who have demonstrated a career of excellence in the activity (para. 6).

Warner went on to say:

The second stage of the construction must be to find solutions to the barriers which prevent diversity from reaching the upper competitive echelon, without compromising the standards of excellence that tradition has bestowed on collegiate debate. A sincere commitment to excellence through diversity must be the long-term priority, if debate is willing to fight the stereotypes [sic] association with providing equal opportunity (para. 7).

This article would become the beginning of the shift from the University of Louisville Debate team to the University of Louisville Malcolm X Debate Society. ${ }^{12}$ Warner (1998) noticed that he was one of a few Blacks who were active within Intercollegiate Policy Debate, even referring to himself as a "token symbol of diversity," and set out to change that (p. 76).

Wanting to "help educate and empower African American students;" Warner set out to alter the nature of Intercollegiate Policy Debate. The mission statement for the program read as follows:

Beginning in Fall 2000, the University of Louisville Debate Society (ULDS) mission will embody the theme of "Debate as Empowerment." ULDS will focus on the participation and development in intercollegiate debate by individuals from underserved communities, with a particular emphasis on African Americans. ULDS will benefit from the unique advantage of having one of the only intercollegiate African American Directors of Debate in the country. ULDS will provide a "homeplace" for students to integrate into an activity historically dominated by those with privilege. ULDS recognizes and resists the privilege of the broader Debate community...(ULDS Brochure)

\footnotetext{
${ }^{12}$ This name change did not occur until 2006, inspired by the influence that debate had on the life of Malcolm X.
} 
The program also underwent a change in recruiting practices to focus on primarily attracting African American students, most of whom had little to no prior debate experience. Warner started by developing a one-time, three credit hour course in the Department of Communication that was cross listed with the Department of PanAfrican Studies entitled, "African American Issues in Intercollegiate Debate." This course, which was separate from the debate program, had roughly thirty students on the roster. The majority of these students were Black but there were also a couple of white students enrolled. Part of the course requirement was to be able to travel to and participate in two debate tournaments. This class became the first cohort of what the larger Debate community has called, the "Louisville Project." While the "Louisville Project" is how most people refer to the new methods that Louisville debate program would eventually develop, the word "project" implies something that is temporal and/or experimental. However, thirteen years later, it is neither of those things. Therefore, this paper will refer to the program by its current title, The University of Louisville Malcolm X Debate Society or University of Louisville Debate team/program.

The debaters initially engaged in most of the traditional norms and procedures. However, instead of speaking at the typical rate of 400 words per minute, the team challenged the notion of speed reading as a practice. The team engaged in a conversational speaking rate and contested any team that sped read against them, making claims that speed reading was exclusionary. The argument was that speed reading made the activity inaccessible to those not trained in debate, including new debaters and anyone that may be interested in viewing a debate, such as: parents or the staff on the campuses where debates took place. 
Additionally, the team would find a racial perspective from which to debate the topic. In other words, whatever the topic, the team would find an argument related to the perspective of Blacks. The topic that year was,

Resolved: The United States federal government should substantially increase its development assistance, including government to government assistance, within the Greater Horn of Africa (Cross Examination Debate Association Wikipedia, 2014, para. 13).

The Louisville affirmative argument was for the United States Federal Government to give government assistance to the Greater Horn of Africa in the form of reparations for the past injustices of slavery. The Louisville debaters were very successful employing this strategy.

That same season, the team travelled to Lawrence, Kansas to participate in The Heart of America Tournament at the University of Kansas. This trip was unique because Warner thought it would be a good idea to bring a professor of Pan-African Studies at the University of Louisville, Dr. Joy Brown, as a guest judge. Dr. Brown had no previous debate training but given the topic area was about Africa, Dr. Brown should have been considered a qualified judge with regards to the content of the debate. Although she had no previous training in Traditional debate norms and procedures, she was given instruction on the format of a debate - things such as speaking order, time limits, and how to fill out a judge's ballot. Unfortunately, the first debate that Dr. Brown judged was a disaster. Following Dr. Brown's decision and oral critique, the losing team from University of Texas-Dallas decided that she was not a qualified judge and began to berate her. She was told that she was not qualified because she had no formal debate training therefore; she did not understand the debate. 
Following that debate, a team from the University of Louisville was scheduled to debate that same team from UT-Dallas for the next round. In that moment, the University of Louisville squad collectively developed another challenge strategy for this debate called the shut-down debate. The shut-down debate is a strategy where the team chooses to not engage in a debate about the topic, but instead has a debate about the unethical actions of the other team. The other Louisville teams agreed to forfeit their next debates and sit in solidarity with the team that would debate the UT-Dallas team. For the next two hours, the Louisville team argued that the actions taken against Dr. Brown were unethical. Even though she was not trained in Intercollegiate Policy Debate, there was a lot that the UT-Dallas team could have learned from Dr. Brown regarding the topic area during her post round discussion. The team concluded that the opposing team's sense of entitlement and disrespectful behavior created feelings of exclusion and alienation and should not be tolerated. The judge made the tough decision to vote against the UT-Dallas debaters and in favor of the University of Louisville team. This became the first of many shut-down debates by the University of Louisville.

The following year, some of these same debaters had to move up to the most competitive level of Debate, varsity, and found their successes dwindle away. At this level, the changes that Dr. Warner had implemented thus far of increasing the number of Black participants in Debate and coaching these students to simply run arguments that came from a racial perspective, were inadequate motivating factors to retain Black students. Students were leaving because of judge bias and a sense of forced assimilation. Both Peter Loge and Brenda Logue in their analysis of debater retention conclude that there is an approximately forty percent involvement by minorities at the novice, or 
beginners level of competition. However, these numbers drop around ten percent for women and minorities as they become eligible for the open division, which is the most advanced level of competition. Jack Rogers (1997) conducted a study to examine judges' perceptions of ability in eight key areas with regard to competitors' gender, race and debate division. The purpose was to measure bias within the dominant culture group that favors competitors that reflect similar dominant "in-group" identity and marginalizes the participation and success of competitors from subdominant "out-group" cultures. The dominant culture that he refers to is that of white males. He concluded that there is a "strong positive bias on the part of white male critics towards what they perceive of as positive behavior exhibited by white, male competitors (p.18)." Rogers goes on to state that this bias is supported by a strong correlation between male competitors' behavior and the positive behaviors associated with competition at the open level. Therefore, not only is the activity comprised of mostly white males, the image of a successful debater in turn aligns with the goals, values, practices, and traditions of white males.

Shelton K. Hill (1997) conducted a study that examined Black student motivation to participate in intercollegiate Debate. The biggest factor in student motivation was the notion of forced assimilation. He identified four areas of cultural differences between Black students and white students, using the Afrocentric versus Eurocentric paradigms: collectivism versus individualism, subjectivity versus objectivity, communicative differences, and difference in cognitive styles. The difference in cognitive styles, as articulated by Hill, is that Blacks often prefer intuitive reasoning over inductive and deductive reasoning. As a result of these differences, Hill argued, "African American debaters are faced with a decision to yield to the written and unwritten demands of debate 
competition, or hold to the demands of African American culture (p. 229)." This forced choice is an example of the concept W.E.B. Du Bois (1903) identified in his classic text, Souls of Black Folk, as double-consciousness. This sense of double-consciousness arises from the debaters being forced to choose between the normative cultural traditions of an American institution and Black cultural traditions in cases where these two cultures do not align with one another. Du Bois describes double-consciousness as follows:

It is a peculiar sensation, this double-consciousness, this sense of always looking at one's self through the eyes of others, of measuring one's soul by the tape of a world that looks on in amused contempt and pity. One ever feels his two-ness,an American, a Negro; two souls, two thoughts, two unreconciled strivings; two warring ideals in one dark body, whose dogged strength alone keeps it from being torn asunder.

The history of the American Negro is the history of this strife - this longing to attain self-conscious manhood, to merge his double self into a better and truer self. In this merging he wishes neither of the older selves to be lost. He does not wish to Africanize America, for America has too much to teach the world and Africa. He wouldn't bleach his Negro blood in a flood of white Americanism, for he knows that Negro blood has a message for the world. He simply wishes to make it possible for a man to be both a Negro and an American without being cursed and spit upon by his fellows, without having the doors of opportunity closed roughly in his face (p. 8-9).

Understanding this, the University of Louisville sought ways to merge Black cultural practices with the competitiveness of Intercollegiate Policy Debate. A space needed to be created for the Black student population to engage in debates from their perspective, utilizing a speaking style that was representative of their culture, and have the possibility of winning while doing so.

The team started this process by infusing hip-hop into its debates. The topic for the 2001-2002 season was:

Resolved: The United States federal government should substantially increase federal control throughout Indian Country in one or more of the following areas: child welfare, criminal justice, employment, environmental protection, gaming, 
resource management, taxation (Cross Examination Debate Association Wikipedia, 2014, para. 13).

The team turned to Native American rap artist Litefoot. While Litefoot was rapping about his experiences as a Native American, his lyrics were relevant to the arguments that the University of Louisville team had chosen to make regarding that year's topic. The team criticized the idea of increasing federal control throughout Indian Country. The argument was that the land was wrongfully stolen from Native Americans and the United States Federal Government should instead offer reparations. The song that the team had chosen was called, My Land (Litefoot, 1996). The students would not just read the lyrics of the song, but they would stop speaking and press play on the compact disc player. In that moment the room would fill with the voice of Litefoot:

This Land Is Our Land

This Land Ain't Your Land

From California To New York Islands

This Land Is Our Land

This Land Ain't Your Land

From California To New York Islands (Urban Lyrics, 2014, para. 2)

The music served two primary functions: as motivation and as an alternative source of knowledge and discourse.

Tricia Rose (1994) argues that hip hop is a hidden transcript, discourse that takes place in disguised form, used to disrupt the dominant public transcript, open dialogue between subordinates and those who dominate. As with most forms of resistance, the team was met with backlash from advocates of Traditional debate. Rose goes on to argue:

These dominant public transcripts are maintained through a wide range of social practices and are in a constant state of production. Powerful groups maintain and affirm their power by attempting to dictate the staging of public celebrations, by feigning unanimity among groups of powerholders to make such social relations seem inevitable, by strategically concealing subversive or challenging discourses, 
by preventing access to the public stage, by policing language and using stigma and euphemism to set the terms of public debate or perception (p. 100).

Debate traditionalists argued that hip hop was bad for Debate. The art form was argued to not be a credible source of knowledge, misogynist, homophobic, and tainted by commoditization. However, the response from the University of Louisville debaters was that the benefits outweighed the negatives associated with hip hop. The Louisville team became very well versed at defending the merits of hip hop as an alternative form of knowledge. Armed with an arsenal of academic scholars (Rose, 1994; Potter, 1995; Shusterman, 1992), the team was able to articulate how their use of hip hop gave a voice to alternative stories within the topic, challenged the image of the subjects of the topic, thus, reshaping the dialogue about "Indian Country." In addition to being a source of experiential knowledge, the music also became a tool of motivation for Black debaters.

Towards the end of that season Jon Bruschke, the Director of Debate from the University of California State-Fullerton and an ally to the Louisville team, suggested to Warner that the Louisville students seemed uncomfortable reading cards in the traditional sense and recommended that the team compose their own speeches from beginning to end. Bruschke believed that the debaters should not have to assimilate in order to be successful. The belief was that the traditional presentation of simply reading long quotes verbatim from various academic sources stripped the power found in the history and nature of oratory in the Black community. The suggestion led to the implementation of the three-tier process described in chapter two.

With a new methodology in place, the debaters welcomed the following year's topic: 
Resolved: The United States federal government should ratify or accede to, and implement, one or more of the following: The Comprehensive Nuclear Test Ban Treaty; The Kyoto Protocol; The Rome Statute of the International Criminal Court; The Second Optional Protocol to the International Covenant on Civil and Political Rights aiming at the Abolition of the Death Penalty; The Treaty between the United States of America and the Russian Federation on Strategic Offensive Reductions, if not ratified by the United States (Cross Examination Debate Association Wikipedia, 2014, para. 13).

The debaters quickly found a relation to the topic by choosing to affirm the abolition of the death penalty. The following is an excerpt of Elizabeth Jones' 1AC (first affirmative constructive):

Facts don't cease to exist just because we choose to ignore them. Racism exists in our society whether we choose to acknowledge it or not. If you are white, you benefit from it. If you are Black, you get - on, whether its health care, housing, education or trying to shop in the mall without being followed...(Courier Journal, 2002, p. H8)

(Jones pressed play on the compact disc player and the voice of Tupac Shakur (1993) rapping his song, 16 on Death Row, was heard):

Bye bye, I was never meant to live.

Can't be positive, when the ghetto's where you live.

Bye bye, I was never meant to be.

Livin' like a thief, runnin' through the streets.

Bye bye, and I got no place to go.

Where you find me? 16 on Death Row.

Dear mama, they sentenced me to death.

Today's my final day, I'm countin' every breath.

I'm bitter cause I'm dyin', so much I haven't seen.

I know you never dreamed your baby would be dead at 16 .

I gotta beef with a sick society that doesn't give a - (A-Z Lyrics, 2014, para. 3).

Jones continued:

A lawyer named David Baldus did a study and found that (Black) defendants charged with killing folks got the death penalty in 11 percent of cases, but if it was a Black person that got killed, the death penalty was given out 1 percent of the time. Like Tupac said, I need someone to tell me, what's a Black life worth? Clarence Munford, the author of 'Race and Reparations,' talks about how the death penalty is a form of genocide against Black folks...Think about how many mothers have lost their child to death row. How many children have lost their fathers to death row? Because the death penalty disproportionately affects Blacks, it disproportionately affects Black mothers and children, too... 
I'm not surprised the United States wouldn't sign the treaty which would abolish the death penalty...100 countries have already abolished, banned or only use the death penalty in exceptional cases. This summer a Black boy who was sentenced to death at age 17 was executed. Did you hear me? 17 years old! That child never had a chance...(Courier Journal, 2002, p. H8) ${ }^{13}$

In 2003 Dr. Warner wrote an essay, “Go Homers, Makeovers or Takeovers?: A Privilege Analysis of Debate as a Gaming Simulation", which served two functions: respond to Alfred Snider's 1984 and 2003 articles that laid out the theoretical foundations of debate as a gaming simulation and to offer a reflection of the challenges that the Louisville debate team had issued to the Debate community up to that point. Warner conceded that debate is a game, however, disagreed with the idea that the way debate functioned was the best enactment of the gaming simulation model. At the heart of Warner's disagreement was a distinction between "rules" and "procedures." Snider (2003) defined the terms as follows, "Rules are required actions and systems, while procedures are generally accepted conventions (p. 27)." Rules include things such as time limits and speech order; whereas, procedures include specific adherence to the topic, what constitutes credible evidence, and appropriate methods of delivery. Warner separated the procedural objections into two categories: substantive and stylistic. Substantive procedures are those that directly affect the strategic and content development of the game. Stylistic procedures include issues related to presentation and what format is appropriate for "qualified" evidence. These procedural objections have become the key distinction between traditional and alternative teams and set the foundations for Warner's reflection.

\footnotetext{
${ }^{13}$ The full excerpt was featured in an article on the Louisville debate team in the Louisville Courier-Journal on December 1, 2002, entitled "Talk Smart" retrieved from the Louisville Debate office archives.
} 
There are three generally agreed upon goals in Academic Debate across the ideological divisions. Those goals are the education that the debaters receive, an agreement to debate the important issues of the topic, and fairness within the game of debate. However, the problems arise when participants do not agree upon what each of those goals mean and how best to achieve them. Upon reflection, Warner concludes that the missing goal is the incorporation of the cultural and social values of the participants. This goal deserves attention as the Intercollegiate Policy Debate community attempts to increase diversity ${ }^{14}$ and retention of underrepresented student populations.

During the 2003-2004 season the University of Louisville debaters had become very skilled at utilizing and defending the three-tier process-academic intellectuals, organic intellectuals, and personal experiences — as a method for incorporating different social and cultural values into Academic Debate practices. However, engaging in debates about the topic and defending the stylistic choices became an overwhelming task.

Recognizing the importance of the topical education as well as the mission to increase meaningful Black participation in Intercollegiate Policy Debate, the team decided to add another component to its strategic arsenal. The team decided to engage in a metaphorical discussion of the topic that allowed them to articulate both a topic advocacy and advocate procedural changes to the way Debate functioned.

The topic that year was,

Resolved: The United States federal government should enact one or more of the following: Withdrawal of its World Trade Organization complaint against the European Union's restrictions on genetically modified foods; A substantial increase in its government-to-government economic and/or conflict prevention assistance to Turkey and/or Greece; Full withdrawal from the North Atlantic Treaty Organization; Removal of its barriers to and encouragement of substantial European Union and/or North Atlantic Treaty Organization participation in

\footnotetext{
${ }^{14}$ Diversity, as used in the CEDA Constitution, is not defined in any specific terms.
} 
peacekeeping in Iraq and reconstruction in Iraq; Removal of its tactical nuclear weapons from Europe; Harmonization of its intellectual property law with the European Union in the area of human DNA sequences; Rescission of all or nearly all agriculture subsidy increases in the 2002 Farm Bill (Cross Examination Debate Association Wikipedia, 2014, para. 13).

The affirmative advocacy for the Louisville team was that the "United States Federal Government should enact a full withdrawal from the North Atlantic Treaty Organization just like the University of Louisville debate team should enact a full withdrawal from the harmful norms of Traditional debate practices." This advocacy statement allowed the team to make direct comparisons between the actions of the United States within NATO and the exclusionary norms used by traditional debaters within the Intercollegiate Policy Debate community. The use of metaphor allowed the team to take an abstract discussion about the topic and use it to inform the ways in which debaters conceptualize reality by applying it to the debate structure.

It is important to note that this chapter is not exhaustive of the various strategies used by Warner and his debaters to challenge the inherent assumptions that guide practices. Nevertheless, these are the practices that have survived over the years and are currently being used as the primary method for engagement. The three-tier process has been a productive method and has had a major impact on the larger Debate community. There have been several schools, such as Towson University, Oklahoma University, and the University of California State-Long Beach, as well as individual debaters that have adopted the three tier methodology (with and without the use of the metaphor) and applied it to various goals over the last thirteen years. Nevertheless, there is still a power struggle between these participants and those who would consider themselves to be a part of the traditionalists within Debate. Most of the debate literature surrounding alternative 
debate has examined its personal and performative implications but little, if any, has incorporated a linguistic lens as a means of understanding how language is used to determine inclusion and exclusion from Debate. 


\section{CHAPTER V \\ COMMUNITY OF DIFFERENCE \\ Debate as a Speech Community}

The Intercollegiate Policy Debate community can be conceived of as a speech community. The highly technical procedures and jargon laden aspects of Debate have a language that can be specific to Debate itself and can be exclusionary to underrepresented populations. By using the speech community model of analysis, this can help one understand the challenges of working with demographically diverse populations. Therefore, this project will use the Debate community as a site for examining how speech communities (un)intentionally suppress and exclude minority members, particularly Blacks.

Membership in a particular identity group occurs when two or more individuals have a shared linguistic system that would include some or all of their language, practices, norms, beliefs, and values. Speech community as defined by Patrick (2002) as being a socially-based unit of linguistic analysis is the term that some linguists have used to refer to these groups. A speech community could be bound geographically (Labov, 1989; Feagin, 1996), nationally (Dittmar, 1976), and socio-culturally (Morgan, 2002).

Verbal communication is not the only tool used to make up a system of communication. According to Rosina Lippi-Green (1997), "language is more than a tool 
for communication of the facts between two or more persons. It is the most salient way we have of establishing and advertising our social identities (p. 5)." This is done in a variety of ways; for instance, through verbal communication, ways of dressing, gestures, signs, facial expressions, written text and symbols. All of these things combine to make up communication between people possible. Particular language patterns and meanings are understood according to the meaning prescribed by factors such as culture (Boas, 1911; Sapir, 1921; Whorf, 1956); the economy (Bourdieu, 1977; Irvine, 1989); cognition (Lakoff, 1988; Croft \& Cruse, 2004); and social constructions (Gumperz, 1982; Hymes 1967).

Michael Silverstein (1985) argues that "language is an unstable mutual interaction of meaningful sign forms contextualized to situations of interested human use mediated by the fact of cultural ideology (p. 220)." The dialogue between speakers of different backgrounds is constantly reiterating and constituting language codes and patterns meaningful to each particular speaker. This is particularly true for Debate. Debate is inherently an oral exchange of ideas and world views from people of diverse backgrounds. Naturally debaters will come across various ideas and world views over the course of their careers. During this time period debaters take from these exchanges aspects that they find productive and useful, thus altering their original language patterns. However, the process for determining what is productive and useful is guided by their particular ideologies. These ideologies are shaped by each individual's relationship to society at large. Therefore, as Silverstein contends, "we must look at their ideas about the meaning, function, and value of language in order to understand the degree of socially shared systematicity in empirically occurring linguistic forms" (p.220). This meaning, 
function, and value can be analyzed in the context of what Norman Fairclough (1989) calls discourse, "a social practice determined by social structures (p. 17)." Fairclough argues that discourse is determined by socially constituted orders of discourse, or sets of conventions associated with social institutions.

Historically, traditional norms and procedures within Debate have determined the orders of discourse for the Debate community. These norms and procedures of debate developed out of a culture of a relatively homogenous group of wealthy, white males. However, the increase in diversity — defined as race, class, gender, sexuality, and those with disabilities - in recent years has shifted Debate into a more heterogeneous community. With the influx of each group has come the potential of different ways of communicating, thus creating a need to shift the norms and procedures of debate to account for these differences. Unfortunately, there is no mechanism in place to guide this shift. As a result, there have been tense conflicts over what constitutes "appropriate" or "productive" language use within Debate. Recognizing that each of these groups has its own relationship to Debate, each group would warrant independent research. This project however, will focus on the conflicts associated with the membership of Blacks in the Debate community. It is important to note that some Black debaters have chosen to participate in the normative practices of debate; therefore, the emphasis here will be on those Black debaters who have elected to engage in alternative debate methods. These methods vary in performance and presentation and thus should not be reduced to an essentialized notion of "Black Debate." Nevertheless, there are cultural discourse patterns that can be found in most of the variations of alternative styles. 
The Debate literature suggests that some of the methods utilized by alternative debaters victimize Debate (Zompetti, 2004), are less productive for the goals of debate competition (Atchison and Panetta, 2009), and do not maximize the benefits that Debate can provide (Harrigan, 2008). Therefore, this research seeks to enter that dialogue and offer an alternative view of the clash of civilizations that is occurring in Debate by arguing that some of the traditional norms and procedures of debate can have the unintended effect of excluding Blacks. ${ }^{15}$

\section{African American English}

\section{African American English (AAE) or African American Vernacular English}

(AAVE) is the term most commonly used to refer to the dialect of English spoken by urban working class Blacks in the United States. While not all Blacks speak AAE, the majority do. AAE traditions have been studied extensively in a variety of disciplines such as Linguistics, Communication, Anthropology, and Education (Labov, 1972; Dillard, 1973; Kochman, 1981; Smitherman, 1986; Morgan, 1994; Norment, 1995; DeCastro-Ambrosetti, 2003). The literature just cited first appeared in the early 1970s; however, prior researchers of AAE had little knowledge of African American speech communities as they attempted to theorize about the language patterns that existed in said community. As a result, the conclusions offered in much of the earlier studies explained the language patterns and behaviors associated with AAE to be a consequence of various social pathologies (Abrahams, 1963). This work failed to take into consideration earlier works by African Americans, particularly Carter G. Woodson. Woodson (1933) in The

\footnotetext{
${ }^{15}$ African American and Black will be used interchangeably in order to maintain the integrity of the linguistics literature that uses the phrase African American.
} 
Mis-Education of the Negro, offered key insights on the subject of language that deserves examination by arguing that there is a connection to the African languages that were brought over by enslaved Africans centuries ago. However, it important to recognize that during the era that Woodson wrote this, success for Blacks was demonstrated by the capability of one to pattern oneself as closely as possible to the communicative norms of educated white elites.

In 1972 William Labov was one of the earliest linguists to introduce AAE, then termed Black English Vernacular, to mainstream education and serve to legitimize its study as a scholarly discipline. In his seminal text, Language in the Inner City: Studies in the Black English Vernacular, he argued that Black children of the inner city "have the same basic vocabulary, possess the same capacity for conceptual learning and use the same logic as anyone else who learns to speak and understand English (p. 201)." This set the stage for a more comprehensive and affirming study of AAE as a legitimate English dialect with historical foundations in the languages of West Africa. Although the literature on AAE has expanded to provide a thorough understanding of its use, there remains a challenge to find value in its use when it conflicts with dominant discourse practices. Therefore, the emergence of AAE within Debate provides a unique opportunity to analyze how normative discourse strategies in Debate create value barriers to the use of AAE. Generally speaking, in communication, people use their own cultural rules and values to guide their words and deeds, even thoughts, and they also use these as standards to judge the words and deeds of others (Zhou, 2008). This makes the following analysis particularly important to understanding debate practices in an increasing multicultural environment. 
In her seminal text, Talkin' and Testifyin': the Languages of Black America, Geneva Smitherman (1986) defined AAE as "verbal strategies, rhetorical devices, and folk expressive rituals which derive from a mutually understood notion of modes of discourse (p. 103)." She identifies four major categories of discourse modes: signifying, call and response, tonal semantics, and narrative sequencing. Signifying is the "verbal art of insult in which a speaker humorously puts down, talks about, needles—signifies on —-the listener (p. 118)." This is done either to make a point or just for fun, but it is understood that whomever is signified on should never take it to heart. Signifying is considered an art because it requires skill and creativity. The better a person's signifying skills, the better his/her rep-reputation. "Signifying may also be synonymous with the following: dropping lugs, joanin, capping, and sounding (p. 119).” The major difference between signifying and the other types is the subtlety of signifying. The message is indirect, hidden. Other characteristics of "signifying include verbal posturing, teaching or sending a message, elements of sarcasm, indirection, circumlocution, metaphoricalimagistic, humor, irony, rhythmic fluency and sound, directed at person(s) present in the situational context, puns, play on words, and introduction of the semantically or logically unexpected (p. 121)." This discourse type can be exhibited through short verbal quips or extended dialogue.

The second discourse type, call and response, is defined by Smitherman as "spontaneous verbal and non-verbal interaction between speaker and listener in which all of the speaker's statements (calls) are punctuated by expressions (responses) from the listener (p. 104)." It is important to note the verbal comments made while the speaker is talking within the process of call and response is not regarded as discourteous behavior. 
"This discourse type can be used to achieve one or more of the following: co-signing, encouraging, repetition, completer, on "time"-psychological time not literal time. Call and response seeks to synthesize speakers and listeners in a unified movement (p.107108)."

Tonal Semantics is the third discourse type identified by Smitherman. It is the "use of voice rhythm and vocal inflection to convey meaning in African American communication. The voice is employed like a musical instrument with improvisations, riffs, and all kinds of playing between the notes. The rhythmic pattern becomes a kind of acoustical phonetic alphabet and gives black speech its songified or musical quality. Black rappers use word sound to tap their listeners' souls and inner beings in the same way that the musician uses the symbolic language of music to strike inward responsive chords in his listeners' hearts (p. 134)." Tonal semantics can be identified by "talksinging, repetition and alliterative word play, intonational contouring, and rhyme (p. 137)."

The final discourse type is narrative sequencing. Smitherman defines narrative sequencing as the relating of events (real or hypothetical) to explain a point, to persuade holders of opposing views to one's own point of view, and in general to "win friends and influence people" (p. 148). Within this discourse style, speakers use their voice, body, and movement as tools to bring the tale to life. "Narrative sequencing may be found in the following: preaching and testifying, folk stories, 'tall' tales, and Toasts (p. 149)." There are several narrative forms that include ghost stories, human interest stories, stories that explain the origin of events and men, and folk tales. 
While there is a discussion still occurring within the linguistic literature as to the value of these discourse types in pedagogical practice that is not the focus of this research. However, examining the use of these discourse types within a specific realm of academia could offer a better understanding of the effects of dismissing AAE. Referring to these discourse types, the next section will provide an analysis of the different communicative strategies between traditional debaters and Black debaters who choose to use alternative strategies.

\section{Black Discourse in Debate}

Prior to the analysis of Black discourse in Debate, it is important to note the differences between rules in Debate and the norms and procedures of debate. As discussed in Chapter Three, Snider (2003) defined the terms as follows, "Rules are required actions and systems, while procedures are generally accepted conventions (p. 27)." There are very few rules, formal requirements, in Debate to which one must adhere. Those rules include time constraints, speaking order and the awarding of one win and one loss per debate by the judge. Everything else is, as one would say in Debate, debatable. Therefore, the practitioners of the Debate community determine which norms and procedures will be adopted, thus which ones have value. As such, an analysis of how those norms and procedures interact with the increase in diversity, particularly Blacks, within the Debate community is a very important one.

This analysis will isolate several norms and procedures that are at the heart of the debate about Debate across styles and ideologies. Utilizing the debate arguments by the University of Louisville Malcolm X Debate program, the following norms have been 
selected as variables: the flow, speed, and line by line refutation. In terms of procedural arguments made in the clash of civilizations debates, the analysis will focus on the criticisms of these new methods taken from the literature.

Norms: The Flow, Speed, and Line by Line Refutation

There are three traditional debate norms when in contrast with the above discourse types, identified by Smitherman, create barriers to the understanding and evaluation of those discourse types: the flow, speed, and line by line refutation. If the purpose of the flow sheet is to track the debate and is the primary tool used to evaluate the debate, then it would follow that it provides the framework for the stylistic and strategic choices that debaters make in an effort to win the debate. The linear nature of the flow sheet organizes the debate, offering a justification for line by line refutation, as defined in Chapter One. It becomes the mechanism by which judges can claim objectivity in their evaluation process. Unfortunately, identifying what gets transcribed onto the flow sheet is a subjective process that could lead to misunderstanding and devaluation of the intended message. If one is unfamiliar with signifying, the indirect nature of this discourse type increases the likelihood that there will be notational error from what is said and how it is said to what gets put onto the flow sheet. For example, "The Louisville debaters repeat traditional practices and engage in a strategic reversal of those practices in an effort to create new meanings and norms (Reid-Brinkley, 2008, p.79)." Unless the judge has a particular way of notating the strategic reversal with the new meanings and norms, a notational error is possible. A notational error of this type 
could have significant implications for the judge's ability to assess the arguments being made.

Additionally, the flow in combination with the speed of delivery, suppresses an integral part of the message that is being communicated in speeches. "The speech rhythms and tonal inflections of Black English (AAE) are, of course, impossible to capture in print (Smitherman, 1986, p. 134)". The effect of tonal semantics is to convey a psychocognitive message. The value is placed on word sound, thus words alone cannot achieve this same effect. Within tone languages, which constitute much of West African languages, speakers rely on the tone with which they pronounce syllables, sounds, and words to convey meaning. The functionality of tone is that it offers sociocultural context to the words being spoken. In other words, it is not just about what is said, but how it is said, who says it, and to whom it is said. "Tonal semantics, in effect, combines emotion and intellect—word sound and word meaning (Smitherman, p. 137).”

As previously mentioned, speed, a common traditional debate practice, is the process of debaters speaking at a rate up to 400 words per minute. The use of speed in debate could change how one would interpret word sound. Since the focus is on maximizing the amount of information presented within the speech, the use of sound to convey meaning is minimized. The importance lies more in what is said as opposed to how it is said.

On the other hand, alternative debaters rely on tonal semantics to convey various levels of meaning. This use of tonal semantics as an important component of oral delivery can lead to those who are not accustomed to listening for those meanings to miss those meanings. For example, the delivery of alternative debaters takes on a holistic 
structure as opposed to the traditional, linear one. Thus, tonal semantics is used to indicate when a speaker has moved to a new point, creating structure for a speech that appears to flow together as one singular thought. Traditional debaters utilize words such as "and" or "next" to indicate this shift. The inability to interpret tonal semantics in this way can lead to notational error.

Additionally, speed can be used to mute emotion making traditional debaters appear to be objective advocates. Decreasing the function of tonal semantics as part of the speech presentation severs the emotional aspects of the words being spoken by removing the word sound. This in turn leaves only the word meaning and could affect the sociolinguistic context of the intended message. On the other hand, the use of tonal semantics for alternative debaters makes their emotion hyper-visible and could be misinterpreted as unnecessary emotion in contrast to the muted speed reading of traditional debaters. The hyper-visibility of these emotions could also lead to a misunderstanding of what emotion is being conveyed and the function of that emotion. For example, speaking loudly could be used to emphasize a particular point or show passion for a particular subject but could be misinterpreted as angry or rude. This has led to alternative debaters being blamed for increasing the hostility within Debate.

As a consequence of line by line refutation being the normative practice for organizing and processing a debate, different presentational structures often create room for notational error. Signifying and narrative sequencing both rely on a holistic, thematic presentation of ideas. This presentation style is in direct contrast to the linear logic used in traditional debate. Attempting to flow these narratives in the traditional sense compartmentalizes and displaces the theme of the narratives being presented, thus 
distorting the intended message of the speaker. Testifying, as a form of narrative sequencing, conveys a theme, is interactive, uses metaphors and analogies, as well as utilizes images and symbols. This creative use of language conflicts with the outline structure of line by line refutation. Therefore, this holistic approach to presentation also increases the likelihood of notational error on the flow.

Procedures: The Personalization of Debate and Topical Engagement Debate scholars agree that debating is a form of empowerment for all of its participants, but especially for those from marginalized populations. However, the gaming aspect of debating creates competition for access to that empowerment across ideologies. The most productive way to understand this power struggle in Debate is to examine the writing of Debate scholars that problematize alternative debate, in general, and alternative Black Debate, more specifically.

First, what does it mean to be alternative? The Merriam-Webster Dictionary (2014) offers three definitions of the term alternative. The first definition is "offering or expressing a choice." The second is "not usual or traditional." Lastly, alternative could mean "existing or functioning outside of the established society (para.1,2,3)." Any and all of these definitions could be true when discussing the new phenomenon of debate practices. It really depends on what perspective one chooses, in other words, the lens by which one comes to know Debate. The first definition implies that those who choose to participate in Debate have a choice as to how they want to engage. While the phrase "not usual or traditional" implies that there is a historical way that participants have engaged in debate and anything outside of those normal means of engaging would be considered 
unusual. Finally, the third definition suggests that anyone debating in ways other than what the community has deemed as acceptable norms would be considered outsiders. The literature has defined three markers of alternative debate: personalizing debate, alternative forms of evidence, and lack of a topical focus (Woods, 2003; Speice and Lyle, 2003; Zompetti, 2004; Newnam, 2005; Harrigan, 2008; and Young, 2011). While alternative forms of evidence have become more widely "accepted" in the community, whether or not they are considered valuable or evaluated properly based on their intended function is still unclear. The other two, personalizing debate and lack of a topical focus, continue to be overt points of contestation within CEDA/NDT Debate, as evidenced by the framework arguments made by more traditional teams.

Joseph Zompetti, a Debate scholar, wrote an article in 2004 that examined the personalized nature of the arguments that the University of Louisville initiated within the Debate community. Zompetti agrees that Debate struggles with diversity but argues that Louisville's claims, that "the traditional norms of debate are exclusionary", are unverifiable and do not justify by themselves the insertion of personalized arguments in debates. Situating the goal of debates to be a forum meant for hypothetical policymaking, Zompetti contends that making debates personal victimizes Debate and ignores deeper, perhaps more important structural problems within the Debate community such as resource disparities.

There are three types of arguments that Zompetti (2004) used to define personalized arguments: "traditional debate excludes certain types of evidence, traditional debate privileges affluent individuals, and traditional debate ignores the reality of many individuals who are already at a disadvantage in the activity (p.28).” The first 
argument type, that "debate excludes certain types of evidence," maintains that the Debate community values academic evidence and devalues other forms of knowledge that come from what Antonio Gramsci (1978) calls organic intellectuals. The type of organic intellectuals being referred to here are the ones that Gramsci identifies as the permanent persuaders, a group of organic intellectuals that grows within the subordinated class(es). He goes on to state, "Organic intellectuals in the subordinated class(es) are defined by social function rather than the characteristics of formal education, cultural distinction, or social status (p. 42)." Alternative debaters have introduced some forms of hip hop as a source of organic intellectualism that provides a perspective that is counter to that of the dominant ideological constructs of the world.

The second argument type argues that "traditional debate privileges affluent individuals." This argument encompasses things associated with material privileges. Some of the material privileges include things such as the financial costs associated with attending debate camps, travelling to a large number of national tournaments, access to the amount of "free time" to prepare for debate tournaments in order to be nationally competitive, etc. As mentioned above, learning the language of Debate requires extensive training, debate camp is one of the mechanisms used to train debaters but camps generally cost between $\$ 1500-3000$ to attend. Additionally, competitive success typically depends upon one's ability to travel to the national circuit tournaments. The reasoning is that the best of the best compete at these tournaments, as opposed to the regional tournament circuit. Lastly, debaters spend anywhere from 40-100 hours per week in preparation for tournaments. Unfortunately, there are many debaters who have 
academic, familial and work obligations outside of Debate that prohibit them from being able to commit that amount of time towards preparing for debates.

Finally, the argument that "debate ignores the reality of many individuals who are already at a disadvantage in the activity" makes claims about the way that traditional debate does not allow for the implications that race, class, gender, sexuality, and disability can have on how Debate, in general, and debate tournaments, more specifically, function. These arguments typically make claims about what types of perspectives and Debate norms develop from positions of privilege. Tim Wise (2005) while discussing his experiences in Debate argues that Debate is an "extraordinarily white" activity (p. 69). He goes on to state,

the reason that I call this process a white one is because white people (and especially affluent ones), much more so than folks of color, have the luxury of looking at life or death issues of war, peace, famine, unemployment or criminal justice as a game, a mere exercise in intellectual and rhetorical banter...kids of color and working class youth of all colors are simply not as likely to gravitate to an activity where pretty much half the time they'll be forced to take positions that, if implemented in the real world, might devastate their communities (p. 71-72).

These three argument types are usually made by debaters identifying themselves as being affected by these patterns of exclusion. Thus, it is believed by debate scholars that these debaters are using their "victimage" to gain a competitive advantage in debate rounds (Zompetti, 2004. p. 30). These scholars have argued that these narratives of exclusion are not contestable because one cannot effectively debate another's personal experience.

Recalling Smitherman's definition of narrative sequencing, as the relating of events (real or hypothetical) to explain a point, to persuade holders of opposing views to one's own point of view, and in general to "win friends and influence people" (p. 148), 
narratives should be considered valuable components of debate strategy and technique. However, while these scholars acknowledge these narratives as important, they fail to accurately understand and portray the function of these narratives, thus missing the value in using narratives in debates. The sociolinguistics literature offers an alternative perspective for understanding the function of these narrative discourses. While most Debate scholars would argue that these narratives in debate only serve as personal testimony, or complaints of oppression, the sociolinguistic literature surrounding identity and language would suggest that these narratives are ways of positioning the self in the context of a larger interactional scheme. Therefore, as Bucholtz and Hall (2005) suggests, when approaching identity—in Debate—to "consider a relational and sociocultural phenomenon (p. 585). This phenomenon emerges and circulates in discourse contexts of interaction rather than as a stable structure located primarily in the individual psyche or in fixed social categories (p. 586)." Conceptualizing personalized arguments in this way allows one to understand that all language interactions in debates communicate at least part of one's identity, whether it is explicit or implicit. Therefore, debates are always "personal". However, criticizing one group of students for positioning their arguments within a larger social, political, or cultural context creates an unfair barrier for inclusion into Debate for that group.

While acknowledging that there is merit in these personalized arguments, Zompetti and others (Atchison and Panetta, 2009) contend that making these arguments inside of the competitive debate rounds personalizes debate, therefore increasing hostility within the activity. These scholars suggest that it would be more productive to situate these dialogues outside of competition in a more "community-based" discussion. 
However, there are two assumptions embedded in this suggestion. One is that there is a clear line of demarcation for when competition begins and when it ends. Unfortunately, the boundaries of competition that are defined as "in a debate round" versus "out of a debate round" are false boundaries. With the proliferation of social media usage, these debates are continuously occurring. While they occur outside of competition, most of these discussions are the same ones occurring within the competition setting. Debaters and coaches are often concerned with how their words and actions can affect their competitive success, whether consciously or subconsciously. The second assumption is that there is a universal sense of community. Unfortunately, when Zompetti (2004) and others minimize these arguments to "complaints", "soliloquies", "ad hominem attacks", "fallacies of composition", "guilt appeals", and ultimately "victimage", they diminish the ability of the discourse used by alternative debate teams to communicate a very complex set of arguments (p.28). This in turn fractures that sense of community because it communicates to alternative debaters that their discourse choices are not valued within the Debate "community".

The second objection to alternative debate involves the lack of topical engagement in debate rounds. Those who oppose alternative debate often argue that their frustrations stem from alternative debaters' "refusal" to debate the topic. There have been a range of suggestions made as to what it means to debate the topic. Some say that broad discussions around the general topic area are sufficient, while others argue that one must defend the hypothetical implementation of United States Federal Government action. The former realizes that debaters come to Debate with various experiences and those experiences help to shape how they choose to debate the topic. This interpretation 
provides debaters with the flexibility to choose the best method for debating the topic.

On the other hand, the latter interpretation prescribes a set rubric for debating the topic. This rubric stems from a particular discoursal style —one most associated with traditional debate.

The linguistic literature on the difference of discoursal style between white and Black students is the notion of topic centered versus topic association (Michaels, 1981; Erickson, 1971). This same distinction could be applied to the different ways that debaters choose to debate the topic. According to Michaels, in a topic centered approach, discourse is centered on a single, clearly identifiable topic. Generally, topic centered discourse is tightly organized, utilizing a linear progression of information that is focused on the description of a single event. She goes on to explain that in a topic association approach, the discourse uses a series of implicitly associated personal anecdotes to discuss the topic. Speakers using this approach mostly have implicit themes, implicit topic shifts and anecdotal association rather than linear description. This overall difference in discourse style could lead one to believe that one is debating the topic and the other isn't when, in fact, both styles would be engaged in topical debate.

The implicit nature of the topic association approach occurs through signifying. Henry Louis Gates (1988) discusses signifying in terms of the Black literary tradition in Chapter Three of his text, The Signifying Monkey: A Theory of African American Literary Criticism. Gates argues that signifying manifests in literature in three ways: an explicit theme or subject matter, an implicit rhetorical strategy, and/or a principle of literary history. Within debates, an implicit rhetorical strategy is most often used to engage debates about the topic. This implicit strategy unfolds through parody, which 
could include repetition, dissemblance and/or imitation. There are two forms of parody:

A) pastiche, which "caricatures the manner of an original without adherence to its actual words" (p. 107), and B) parody proper, "in which an original, usually well known, is distorted, with the minimum of verbal or literal change, to convey a new sense, often incongruous with the form" (p. 107). One of the major functions of the use of such parody in Debate is a phrased coined by M. Mikhai Bakhtin and used by Gates, called hidden polemics. In hidden polemics,

the other speech act remains outside the bounds of the author's speech, but is implied or alluded to in that speech. The other speech act is not reproduced with a new intention, but shapes the author's speech while remaining outside its boundaries. . . . In hidden polemics, the author's discourse is oriented towards its referential object, as in any other discourse, but at the same time each assertion about that object is constructed in such a way that, besides its referential meaning, the author's discourse brings a polemical attack to bear against another speech act, another assertion on the same topic (Gates, p. 111).

Therefore, literal interpretations of the topical discussions using the association approach, causes the listener to miss or misinterpret the meaning of the words being spoken. However, the benefit of such approach is that it allows a new narrative space for the "Black Experience." This new narrative space is used to alter or challenge the inaccurate or inadequate representations held about the "Black Experience" from those who are not Black.

The biggest defense for the set prescriptive rubric for debating the topic is the theory of switch-side debate (SSD). According to Casey Harrigan (2008) that rubric "requires students to argue both for and against a given topic during the course of a season. As part of this process, it has been generally accepted that student debaters are allowed, if not encouraged, to 'step outside of the box' and gain additional insight into controversial issues during contest rounds by arguing on the behalf of positions that they 
do not personally hold (p. 37)." Aside from the fact that SSD does not account for difference in discoursal styles, there are a couple of other reasons that SSD does not account for difference. The premise behind the benefits of SSD is that this format encourages debaters to argue on behalf of positions that they do not personally hold; allowing for pragmatic, pedagogical, and social benefits. In theory, SSD is productive and beneficial. However, the way that the topic is constructed limits the pedagogical and social possibilities of SSD.

Understanding the process of topic selection is a pre-requisite for examining the implications of topic construction on the benefits of SSD. The topic selection process occurs in several stages. The first stage is an open call for papers, where any member of the community can submit a controversy paper. According to the CEDA National website, the goal of this stage of the process is to develop papers that outline the 'problem areas' involved with a public policy controversy and provide some guidance as to how such a topic might develop. A controversy paper is then selected by a mail ballot of all CEDA member schools. During the second stage the selected controversy is researched with an interest in developing the possible specific propositions (or resolutions) for the coming season in the form of wording papers. The committee and community will both be invited to prepare such wording papers. Finally there is a topic meeting, open to the membership, to finalize the slate of specific propositions to be voted on by all of the CEDA member schools.

On face, this is a neutral process that allows for all of the CEDA membership to have an "equal" voice in the process of topic selection. Unfortunately, the break down occurs at the level of the voting, much like in the larger "democratic" society. Voting 
becomes a numbers game whereas, the majority has voting power. While this is true of any democratic voting process, the ability to maintain a majority has historically advantaged traditional debaters and coaches. Thus the language of the topic has been constructed in ways that reinforce the pedagogical and social values of traditional debate. At the heart of the arguments in favor of or against SSD lies the topic.

Historically, the topics that have been selected have been constructed utilizing the active voice as opposed to a passive voice. An active voice example would be, "Resolved: The United States Federal Government should substantially increase statutory and/or judicial restrictions on the war powers authority of the President of the United States." A passive voice example would be, "Resolved: The war powers authority of the President of the United States should be substantially restricted." The active voice topics require debaters to defend that the United States Federal Government "do something" in a more limited capacity, whereas a passive voice topic could allow debaters the opportunity to defend a variety of interpretations of "something being done" by or to the United States Federal Government. The active voice topic always gives the agency to act to the United States Government. For students that see themselves as having the possibility to access these positions of power, acquiring these skills become empowering. However, many marginalized students come to Debate from communities that have historically been excluded from these positions of power. Having a passive topic that removes the agency from the United States Federal Government and allows debaters the flexibility to choose who has agency thus becomes more empowering to this population of students. These students would then be more motivated to participate in the process of 
debate through which they can acquire a variety of skill sets from politician to community activist.

Secondly, the literature base used to construct the topic has failed to include perspectives found within the race literature, such as the legal and political scholarship of Derrick Bell (1992), Cornel West (1994), and bell hooks (1995). Very little, if any, attention has been given to Critical Race Theory or Critical Legal Studies within the chosen controversy areas, such as Immigration and Supreme Court Cases. Even when topic papers are submitted that do include this literature, they are rarely, if ever selected in the voting process. This is important to the conversation of debating the topic in that the topic paper sets the definitional guidelines of what is considered topical. If the topic paper is limited to the language and perspective of the dominant, then so too will the debates be limited to the language and perspective of the dominant. Thus, it could be argued that the topic does not account for the discourse strategies of marginalized populations and could be an additional source of exclusion from Debate. 


\section{CHAPTER VI CONCLUSION AND DISCUSSION}

The important role that Debate has played throughout history in training students to become the nation's most prominent leaders and active citizens requires special attention to how these students are trained. Debate is the training ground for the future movers and shakers of society. Therefore, Debate educators have a responsibility to ensure that the ways in which these students think about the policy making process is inclusive of a diversity of values, perspectives, and cultures. Altering the perspectives of debaters during their intercollegiate debate careers could have positive long term effects on the ways they choose to interact with diverse members of the larger society. Debate is no longer an activity mostly comprised of wealthy, white males. Within the last decade and a half, Debate has had an increase in demographically diverse populations. Thus, it is necessary that Debate has a process for valuing the voices of all of its students.

Just like the interracial debates of the early twentieth century provided Blacks with a platform to disprove stereotypes about Black intellectual inferiority, Debate continues to provide a stage for Black students' voices. However, these students must not be forced to assimilate into the traditional norms of Debate to be considered valuable members of the Debate community. In order for Debate to continue to be relevant well into the future, there has to be a transformation in the culture of the community. This 
culture must transition away from a community that holds onto stagnate notions of universalism to one that embraces notions of difference.

This process began in 2000 when Dr. Ede Warner, then Director of Debate at the University of Louisville, had a vision to bring Debate to Black students. Successfully recruiting a new cohort of Black students in Debate, Warner found that these students were frustrated with being forced to assimilate into the traditional norms of the activity in order to be successful. The culture of Debate was not inclusive of the values and perspectives of his students. Thus, in order to retain Black students, challenges to the norms and procedures of debate were necessary. Warner and his students were not only successful in challenging traditional norms and procedures but they were also innovative in the successful creation of alternative methods that are most representative of the lives that they experience. The success of this new model of Debate has led to increased tensions and hostilities throughout Debate in what is now called the clash of civilizations. An examination of the clash of civilizations debates is not only necessary for the recruitment and retention of the Black student population but Debate at large. This new model of debate, alternative debate, has been instrumental in the recruitment of other diverse groups, such as: Latinos, Native Americans, disabled populations, and LGBT students. Additionally, the inclusion of different values and perspectives adds another level of training for the future movers and shakers of society. If debaters are trained to make policy for diverse populations, then understanding the difference in cultures, values and perspectives of these groups is an invaluable experience. Ultimately, these standpoints are necessary for the growth and development of every member of the Debate community. Unfortunately, the backlash to alternative debate has overshadowed the 
benefits of including alternative debate for much of the community. Therefore, research on the clash of civilization debates is an essential and timely endeavor.

The speech community model of analysis has been a productive model for examining the ways in which the prioritizing of traditional debate norms and procedures has served to exclude Black discourse, values, and perspectives. While it is not always an intentional act of exclusion, the effects can often be just as injurious. The debate about Debate, that has been ongoing within Intercollegiate Policy Debate, has provided an excellent opportunity to examine how the exclusion of different discourse strategies can ultimately lead to the exclusion of an entire culture, their values, and their experiences.

With the recent growth of the Black student population in Debate, the community has been introduced to new methods of debate. As a result of the increased use of alternative methods, the discussions regarding the community's best practices have become a site of contention for many of its members. The hostility surrounding the debate about Debate is at an all-time high and the community is split along the lines of stylistic choice. Additionally, this split has also segregated the community along lines of race. The effects of this conflict have left these Black students stigmatized and constantly fighting to be recognized as valuable members of the Debate community. In this regard, the Debate community has failed to become the open and inclusive community that it prides itself on being. Not only are these Black debaters negatively affected, but the entire community risks losing the potential benefits that come from the inclusion of alternative perspectives. 
This research isolates specific norms within traditional debate. Specifically, the research targets the use of the flow, speed, and line by line refutation. To be clear, it is not the norms in and of themselves but the ways in which these practices have been used at the exclusion of alternative methods of debate for Black students. Traditional debate practices have often been defended, by coaches and debaters alike, as the best method to train debaters in the process of policy making. However, most of the rationale for this defense depends upon a universal understanding of the purpose of Debate. There are various factors that determine why each student chooses to participate in the activity and what he/she chooses to get out of the activity. The ontological positioning of traditional debate practices as "the best" inhibits debate traditionalists from understanding the epistemological challenges that these alternative debaters are issuing.

Additionally, a second layer of analysis has been conducted in terms of some of the procedural criticisms launched against alternative debaters from the more traditional practitioners of the activity. These criticisms include the personalization of Debate and the lack of a topical focus. These two criticisms are at the heart of the clash of civilizations debates. The clash of civilizations debates are some of the most productive and educational debates that occur within the Debate community. The heightened tensions and hostilities that come with these debates often overshadow the benefits of these debates. These debates are where values and perspectives clash. Within these discussions, debaters are learning that their way of viewing the world is not the only way to view the world. A lot of times this process is painful. However, this does not mean that the process is not valuable. Learning about different cultures, perspectives, and values only adds to the benefits that students receive as a result of their debate training. 
Working against the grain, these debaters have managed to persevere and succeed within Debate and their respective careers post-graduation. The image of the successful debater is no longer only aligned with the goals, values, practices, and traditions of white males as articulated by the study conducted in 1997 by Jack Rogers. There are now more successful Black debaters within the activity than there have been since the era of HBCUs' participation in Debate. There have been a number of historical firsts achieved within Debate by students at various universities since the development of the three-tier process by the University of Louisville:

- 2004, First time that two African American women won the $1^{\text {st }}$ and $2^{\text {nd }}$ speaker awards at the CEDA National Tournament, University of Louisville

- 2012, First African American woman to receive an at-large bid (top 16 teams nationally) to the NDT, Emporia State University

- 2013, First time that two African American, openly gay males won the National Debate Tournament and the first time that any team has ever won both national titles (CEDA and NDT) in the same season, Emporia State University

- 2013, First time an African American woman has won the National Female Coach of the Year Award for CEDA, University of Louisville

- 2014, First time that two African American females won the CEDA National Tournament, Towson University

- 2014, First time that an African American won the top speaker at the NDT, Oklahoma University

Additionally, graduates of the first cohort of debaters from the 1999-2000 University of

Louisville Malcolm X Debate team have gone on to become lawyers, community organizers, educators, a journalist, a chemist, and a collegiate Director of Debate.

Yet, few members of the Debate community understand the history, nature, and function of the strategies used by Black students to the point of isolating and stigmatizing this student population. Therefore, until the judging pool at tournaments becomes more representative of the student population then judges should be required to attend professional development seminars that assist with training in alternative methods of 
debate or there needs to be a change to the evaluation process of these debates. It is important to acknowledge that there is a portion of the community that is working on behalf of these students. There has been a group of non-Black Debate community members, who believe in the value of alternative debate methods. This is evident by the fact that more judges have been willing to vote for Black debaters who use alternative methods. However, within this group, more training is still needed. While they may be voting in favor of these debaters, the post round discussions indicate that there is still a level of unfamiliarity with the values, perspectives, and experiences of Black culture. Additionally, there needs to be a concerted effort by the topic committee to ensure that submitters of controversy papers for the upcoming topics expand their literature base to include perspectives from critical race scholars.

Debate researchers need to continue conducting research on the alternative methods used in Debate. First, researchers need to broaden the scope of what defines "good" debate. Restricting the standards of "good" debate to traditional methods that do not fully serve the entire population of students is limiting the potential for Debate to be empowering to all. Second, researchers should identify the types of alternative methods that are most frequently used in Debate. While this research focuses on the strategies used by Black debaters, other underrepresented groups are entering the Debate community and bringing in other culturally specific methods of debate. These students have been met with similar difficulties. Third, researchers need to examine how the culture of Debate impacts student participation within the activity. The amount of time that one spends within Debate is extensive. Thus, fostering a climate that is inclusive and welcoming is a necessary step to ensuring the continued growth of the activity. Finally, 
it is not solely the responsibility of these underrepresented groups to find solutions to these problems. Every member of the Debate community must be made accountable. Only when the Debate community finds ways to valuably include difference in Debate will the activity be able to maximize its benefits to academia and society at large. 


\section{REFERENCES}

Abrahams, R. D. (1963). Deep Down in the Jungle: Negro Narrative Folklore from the Streets of Philadelphia. Chicago: Adline Publishing.

Abrams, N. (1995). Antonio's B-Boys: Rap, Rappers, and Gramsci's Intellectuals. Popular Music and Society, 4, 1-19.

Atchison, J., \& Panetta, E. (2009). Intercollegiate Debate and Speech Communication: Historical Developments and Issues for the Future. In A. Lunsford, K. H. Wilson, \& R. A. Eberly (Eds.), The SAGE Handbook for Rheotrical Studies (pp. 316-334). Thousand Oaks: SAGE Publications.

Barker, L., Jones, M. H., \& Tate, K. (1999). African Americans and the American Political System. Upper Saddle River: Prentice Hall.

Bartanen, K. (1995). Developing Student Voices in Academic Debate Through a Feminist Perspective of Learning, Knowing and Arguing. Contemporary Argumentation and Debatae, 16, 1-13.

Beil, G. (2008). Wiley College: The Great Debaters. East Texas Historical Journal, $46(1)$.

Bell, D. (1992). Faces at the Bottom of the Well: the Permanence of Racism. New York: Basic Books.

Boas, F. (1911). The Mind of a Primitive Man. New York: The MacMillan Company.

Bourdieu, P. (1977). Outline of a Theory of Practice. Cambridge: Cambridge University Press.

Branham, R. (1995). "I Was Gone on Debating": Malcolm X's Prison Debates and Public Confrontations. Argumentation and Advocacy, 31, 117-137.

Brawley, B. G. (1917). A History of Morehouse College, Atlanta. The Atlanta Baptist College Press.

Bucholtz, M., \& Hall, K. (2005). Identity and Interaction: A Sociocultural Linguistic Approach. Discourse Studies, 7(4-5), 585-614.

Coomes, M. (2002, December 1). Talk Smart. The Courier-Journal, p. H1 and H8.

Croft, W., \& Cruse, D. A. (2004). Cognitive Linguistics. Cambridge: Cambridge University Press. 
Cross Examination Debate Association. (2014). CEDA Constitution. Retrieved May 2014, from Cross Examination Debate Association: http://www.cedadebate.org/files/2014Constitution.pdf

Cross Examination Debate Association. (2014). Cross Examination Debate Association. Retrieved June 2, 2014, from Wikipedia: http://en.wikipedia.org/wiki/Cross_Examination_Debate_Association

DeCastro Ambrosetti, D. (2003). Sociolinguistic Foundations to African Centered Pedagogy: A Literature Review. The High School Journal, 86, 31-48.

Dillard, J. L. (1973). Black English: Its History and Usage in the United States. New York: Random House.

Dittmar, N. (1976). Sociolinguistics: A Critical Survey of Theory and Application. London: Arnold.

Du Bois, W. (1903). The Souls of Black Folk. New York: Library of America.

Erickson, F. (1971). Studying Black Rhetoric and Logic: An Anthropological Approach to Contrastive Analysis. Paper delivered at American Educational Research Association. New York City.

Evans, R. (2011). Forum Post. Retrieved 2013, from Cross Examination Debate Association: www.cedadebate.org

Fairclough, N. (1989). Language and Power. London: Longman Group.

Farmer, J. (1985). Lay Bare the Heart: An Autobiography of the Civil Rights Movement. New York: Arbor House.

Feagin, C. (1996). Peaks and Glides in Southern States Short-a. In G. Guy, C. Feagin, D. Schriffin, \& J. Baugh, Towards a Social Science of Language: Papers in Honor of William Labov (pp. 135-160). Amsterdam: John Benjamins.

Freeley, A. D., \& Steinberg, D. (2005). Argumentation and Debate: Critical Thinking for Reasoned Decision Making. Wadsworth: Cengage Learning.

Freeman, K., \& Cohen, R. T. (2001). Bridging the Gap Between Economic Development and Cultural Empowerment: HBCUs Challenge for the Future. Urban Education, 36(5), 585-596.

Gates, H. L. (1988). The Signifying Monkey: A Theory of African-American Literary Criticism. Oxford: Oxford University Press.

Gramsci, A. (1978). The Intellectuals. In S. P. Hier (Ed.), Contemporary Sociological Thought: Themes and Theories (pp. 49-57). Toronto: Canadian Scholars' Press Inc.

Gumperz, J. J. (1982). Discourse Strategies. Cambridge: Cambridge University Press. 
Harrigan, C. (2008). Against Dogmatism: A Continued Defense of Switch Side Debate. Contemporary Argumentation and Debate, 29, 37-66.

Herder, R. (2004). The New Sophistry: High School Debate as Techne. A Thesis Submitted to the University of Miami.

Hill, S. K. (1997). African American Students' Motivation to Participate in Intercollegiate Debate. The Southern Joournal of Forensics, 2, 202-235.

hooks, b. (1995). Killing Rage: Ending Racism. New York: Henry Holt and Company.

Hymes, D. (1967). Models of the Interaction of Language and Social Setting. Journal of Social Issues, 23(2), 8-38.

Irvine, J. T. (1989). When Talk Isn't Cheap: Language and Political Economy. American Ethnologist, 16(2), 248-267.

Jordan, B., \& Hearn, S. (1979). Barbara Jordan: A Self-Portrait. Garden City: Doubelday.

Kochman, T. (1981). Black and White Styles in Conflict. Chicago: University of Chicago Press.

Labov, W. (1972). Language in the Inner City: Studies in the Black English Vernacular. Philadelphia: University of Pennsylvania Press.

Labov, W. (1989). The Exact Description of the Speech Community: Short-a in Philadelphia. In R. Fasold, \& D. Schiffrin, Language Change and Variation (pp. 1-57). Amsterdam: John Benjamins.

Lakoff, G. (1988). Cognitive Semantics. In U. Eco, Meaning and Mental Representation. Bloomington: University Press.

Lee, E. (1998). Memoir of a Former Urban Debate League Participant. Contemporary Argumentation and Debate, Forum, 93-96.

Lippi-Green, R. (1997). English with an Accent: Language, Ideology, and Discrimintation in the United States. London and New York: Routledge.

Litefoot. (1996). My Land. Retrieved February 24, 2014, from Urban Lyrics: www.urbanlyrics.com/lyrics/litefoot/myland.html

Loge, P. (1991). An Examination of Black Participation in CEDA Debate. Contemporary Argumentation and Debate, 12, 79-87.

Logue, B. (1987, May 18-21). Minority Students in CEDA Debate: Involvement, Success, and Barriers. A Paper Presented at the Annual Meeting of the Eastern Communication Associaation. Syracuse, New York. 
Matsuda, M. (1987). Looking to the Bottom: Critical Legal Studies and Reparations. Harvard Civil Rights-Civil Liberties.

Michaels, S. (1981, December). "Sharing Time": Children's Narrative Styles and Differential Access to Literacy. Language and Society, 10(3), 423-442.

Morgan, M. (1994). Theories and Politics in African American English. Annual Review of Anthropology, 23, 325-345.

Morgan, M. (2002). Language, Discourse, and Power in African American Cultures. Cambridge: Cambridge University Press.

Nation. (1999). Chronicle of Higher Education: The Almanac Issue.

National Association for Urban Debate Leagues. (2014). Our Results. Retrieved May 2014, from National Association for Urban Debate Leagues: http://urbandebate.org/Our-Results

Newman, W. (2005, November 19). Debate Style and the Citizen Activist: Paradigm Shift of Paradigm Lost? A Paper Presented at the 91 st Annual National Communication Association Conference.

Norment Jr., N. (1995, May). Features of African American Students' Writings. Journal of Black Studies, 25(5), 558-576.

Parker, J. W. (1955). The Status of Debate in the Negro College. The Journal of Negro Education, 24(2), 146-153.

Patrick, P. L. (2008). The Speech Community. In Handbook of Language Variation and Change. Oxford: Blackwell.

Polson, D. (2012). Longing for Theory: Performance Debate in Action. Dissertation submitted to the University of Maryland, Baltimore County.

Potter, R. (1995). Spectacular Vernaculars: Hip-Hop and the Politics of Postmodernism. Albany: SUNY Press.

Reid-Brinkley, S. (2008). The Harsh Realities of Acting Black: How African American Policy Debaters Negotiate Representation Through Racial Performance and Style. Dissertation submitted to the University of Georgia.

Rogers, J. (1997). A Community of Unequals: An Analysis of Dominant and Subdominant Culturally Linked Perceptions of Participation and Success within Intercollegiate Competitive Debate. Contemporary Argumentation and Debate, $18,1-22$.

Rose, T. (1994). Black Noise: Rap Music and Black Culture in Contemporary America. Hanover: University Press of New England.

Sapir, E. (1921). Language: An Introduction to the Study of Speech. New York: Harcourt Brace. 
Shakur, T. (1993). 16 on Death Row. Retrieved March 13, 2014, from A-Z Lyrics: www.azlyrics.com/lyrics/2pac/16ondeathrow.html

Shusterman, R. (1992). Pragmatist Aesthetics: Living, Beauty, and Rethinking Art. Oxford: Blackwell.

Silverstein, M. (1985). Language and the Culture of Gender: At the Intersection of Structure, Usage, and Ideology. In E. Mertz, \& R. Parmentier (Eds.), Semiotic Mediation: Sociocultural and Psychological Perspectives (pp. 219-259). Orlando: Academic Press.

Smitherman, G. (1986). Talkin and Testifyin: the Language of Black America. Detroit: Wayne State University Press.

Snider, A. (1984). Ethics in Academic Debate: A Gaming Perspective. National Forensic Journal, 1, 121.

Snider, A. (2003, Sept). Gamemaster: It Is You. Contemporary Argumentation and Debate, 24, 17.

Solt, R. (2004). Debate's Culture of Narcissism. Contemporary Argumentation and Debate.

Speice, P., \& Lyle, J. (2003). Traditional Policy Debate: Now More Than Ever. Retrieved from Debaters Research Guide: http://groups.wfu.edu/debate/MiscSites/DRGArticles/SpeiceLyle2003htm.htm

Stepp, P. (1997). Can We Make Intercollegiate Debate More Diverse? Argumentation and Advocacy, 33(4), 176-191.

Stepp, P., \& Gardner, B. (2001). Ten Years of Demographics: Who Debates in America. Argumentation and Advocacy, 38, 69-82.

Terrazas, M. (2005). Laura Bush Praises Urban Debate Program. Emory Report.

Warner, E. (1998). On Preserving Identity, Debate, and Finding Home. Contemporary Argumentation and Debate, 76-79.

Warner, E. (2000). A Vision for the future. Retrieved July 01, 2013, from National Debate Tournament: groups.wfu.edu/NDT/Articles/warner.html

Warner, E. (2000). University of Louisville Debate Society. Brochure.

Warner, E., \& Bruschke, J. (2001). Gone on Debating: Competitive Academic Debate as a Tool of Empowerment. Contemporary Journal of Argumentation and Debate, $22,1-28$.

West, C. (1994). Race Matters. New York: Vintage Books.

Whorf, B. L. (1956). Language, Thought, and Reality: Selected Writings of Benjamin Lee Whorf. (J. Carroll, Ed.) MIT Press. 
Wise, T. (2005). White Like Me: Reflections on Race from a Privileged Son. Berkley: Counterpoint Press.

Woods, S. (2003). Changing the Game?: Embracing the Advocacy Standard. Contemporary Argumentation and Debate, 24, 85.

Woodson, C. G. (1933). The Mis-Education of the Negro. Washington, DC: The Associated Publishers.

X, M., \& Haley, A. (1965). The Autobiography of Malcolm X. New York: Grove Press.

Young, K. (2011). Impossible Convictions: Convictions and Intentionality in Performance and Switch-Side Debate. Contemporary Argumentation and Debate, $1-44$.

Zhou, Y. (2008, July). The Impact of Cultural Transfer on Cross Cultural Communication. Asian Social Science, 4(7), 142-146.

Zompetti, J. (2004). Personalizing Debating: Diversity and Tolerance in the Debate Community. Contemporary Argumentation and Debate, 25, 26-39. 


\section{APPENDIX I}

\section{SAMPLE PAIRING}

\section{Rd 8}

\section{Start time: 7:15 PM EDT}

\begin{tabular}{|c|c|c|c|}
\hline Room & Aff & Neg & Judge \\
\hline Ballantine 215 & Oklahoma WL & Towson JR & Martel, Alex \\
\hline Sycamore 108 & Harvard BN & Cal State Fullerton RR & Taylor, James \\
\hline Ballantine 305 & Stanford GL & Towson BU & Voeller, Kyle \\
\hline Ballantine 310 & NYU ZD & Northern Iowa SS & Koehle, Joe \\
\hline Ballantine 322 & Wake Forest CL & Missouri - Kansas City AF & Denney, Ashley \\
\hline Ballantine 238 & Kansas BC & Oklahoma RY & Chase, Allie \\
\hline Ballantine 317 & Puget Sound BQ & Kansas HR & Cooper, Deven \\
\hline Ballantine 231 & Kansas HW & UT Dallas LO & Munday, Matt \\
\hline Ballantine 246 & Trinity RS & Kansas CD & Steiner, Rebecca \\
\hline Ballantine 013 & Towson TW & Liberty CE & Sciullo, Nick J. \\
\hline Ballantine 307 & Binghamton EB & Wyoming MP & Copenhaver, Roger \\
\hline Ballantine 222 & Michigan CB & San Francisco State/Irvine AP & Maurer, Sam \\
\hline Ballantine 232 & Kansas State KM & Kansas KS & Fifelski, Kurt \\
\hline Swayne East 009 & Fresno State HT & Texas JS & Dunn, Izak \\
\hline Ballantine 235 & Oklahoma CO & Pittsburgh BW & Carter, Marvin \\
\hline Ballantine 237 & Minnesota MW & Dartmouth College CK & Kennedy, Sean \\
\hline Ballantine 240 & Texas KS & Wyoming DM & Bankey, Brendon \\
\hline Ballantine 245 & Oklahoma SB & Liberty $\mathrm{AB}$ & Awsare, Shree \\
\hline Ballantine 304 & Oklahoma CL & Michigan MM & Kennedy, Patrick \\
\hline Ballantine 344 & UT San Antonio MP & Lindenwood NW & Weitz, Mike "Shooter" \\
\hline Ballantine 319 & Central Oklahoma BH & Whitman College BM & Topp, Sarah \\
\hline Sycamore 0008 & Wayne State NW & UT San Antonio CR & Tomik, Keegan \\
\hline Ballantine 331 & Arizona State CR & James Madison BP & Montee, Andy \\
\hline Ballantine 347 & Kansas MB & Wake Forest BS & Stanley, Justin \\
\hline Sycamore 002 & Cal State Fullerton GR & Wake Forest SV & Allsup, Andrew \\
\hline Ballantine 336 & Whitman College LT & Dartmouth College MM & Box, Brian \\
\hline Ballantine 333 & Kansas State SS & Kansas City Kansas CC FG & Ortiz, Kate \\
\hline Ballantine 330 & Whitman College DK & Southern California OP & Allen, Sam \\
\hline Ballantine 314 & North Texas CS & George Mason BW & Vincent, Christopher \\
\hline
\end{tabular}


APPENDIX II

SAMPLE FLOW SHEET

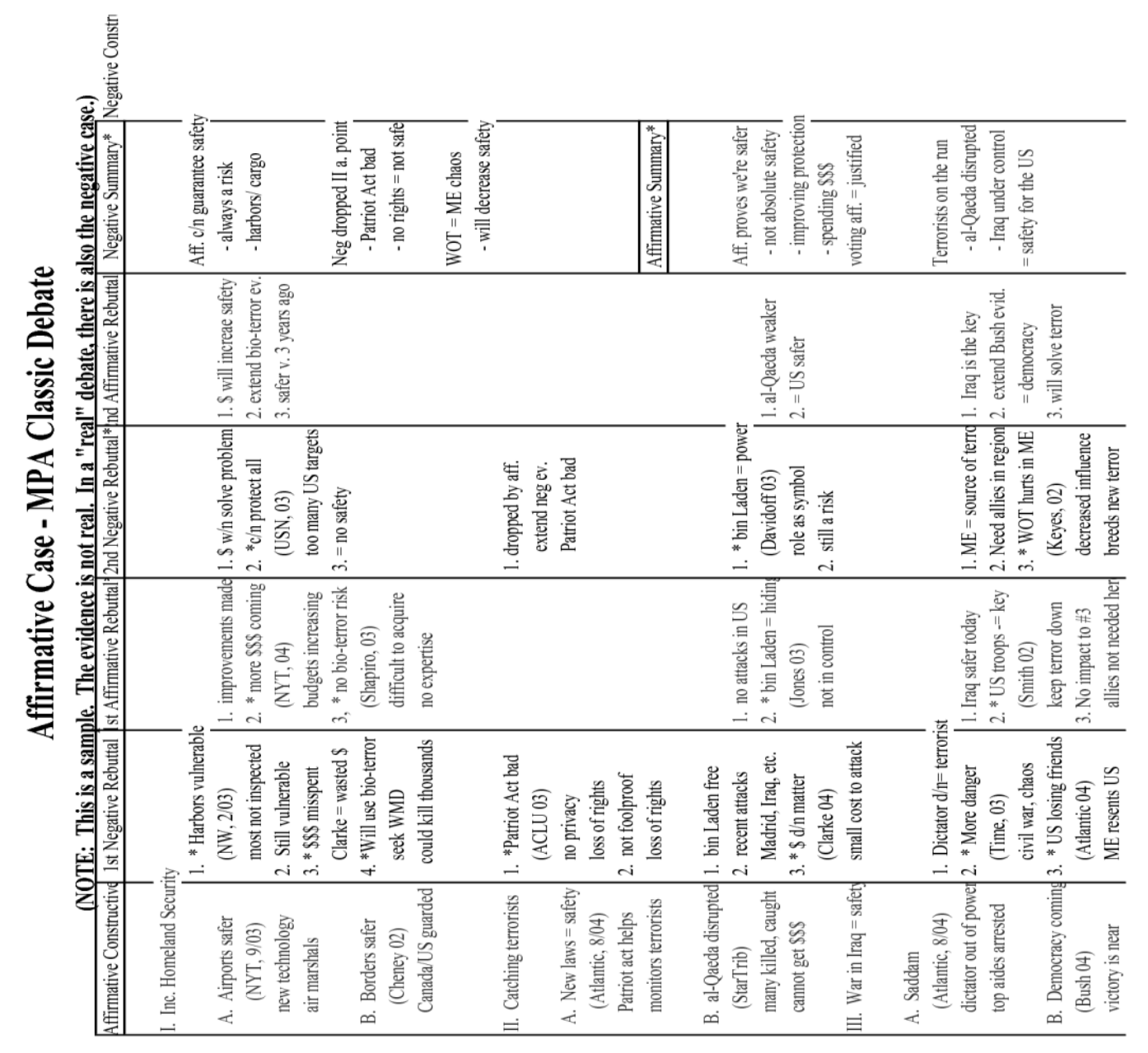




\section{APPENDIX III}

\section{SAMPLE JUDGING PHILOSOPHY}

Samford University

13 years judging

I think about debate a lot, I re-wrote my judging philosophy about five times last year and was never really satisfied. The basic rule I try to abide by is that I can be persuaded to vote on any argument, and that teams are best left to "doing their own thing" in front of me. I have several pre-dispositions and biases, but generally teams are best left to trying to execute the strategies they are most comfortable with and modify them to my expectations and standards, rather than start wholesale.

Topicality/Theory: Probably my strongest bias is that an affirmative must be topical. While I have voted on $\mathrm{T}$ is genocide, the reality is that in a debate between teams of roughly even caliber that fully debate out this issue, the negative should win that the Affirmative must be topical. With that said, in terms of evaluating T, I am more in the reasonability camp than competing interpretations. I think an affirmative that is well grounded in the literature, that uses contextual evidence to prove its topicality claim, and that illustrates why any loss of ground is either trivial or unimportant, should win on topicality. On theory, I am troubled by the prevailing paradigm that judges should err negative on every theory question.

Counterplans: I am growing increasingly concerned about kinds of counterplans that make the Affirmative job too difficult, especially when those counterplans distort the literature base of answers the affirmative can provide to them. For example, I think Counterplans that take US action and then also have other countries provide international FIAT are suspect. I am troubled by the trend toward multiple conditional counterplans. I am unconvinced that it is harder to be negative (Larson's statistics and the Bruschke page confirm that the aff. is winning less than 50\% of debates on this topic). A common thread for me on both topicality and theory is that I prefer debates about "evidenced clash" and interpretations that lead to that result are superior. Counterplans that seek to avoid "evidenced clash" or that reduce a debate to a handful of cards that are tangentially related to anything on the topic are suspect.

All this said, I vote for "suspect" counterplans every weekend, and usually the Negative can muster enough answers in the block to make these counterplans work for them. 1ar's seem unwilling to make the time investment necessary to make these arguments winners, however this part of the judging philosophy was designed to encourage them to consider trying, especially when neg. answers are thin or unpersuasive.

Kritiks/Performance: I am an excellent judge for critical teams, and not a very good judge for performance teams. If you attack the underlying assumptions or discourse of an affirmative case with strong evidence and a clearly articulated alternative, you will do 
well in front of me. I am not a big fan of "framework" as an affirmative answer to kritiks, at least the ways I have seen it argued. Philosophical and discursive questions seem important to understanding policymaking, and trying to divorce the two seems counterproductive. At the same time, teams that challenge flowing, the use of evidence, and/or structural inequities tend to do very poorly in front of me. In addition, I am troubled by teams that attack other debaters personally.

Explicit Performances: This section was added upon Sherry's request to the recent discussion about explicit material in debates. Although I am quite unfamiliar with the circumstances from which this scenario has arisen, I feel strongly that we should create non-hostile environments in debate. I realize a balancing act needs to be played, and I feel the overwhelming majority of debates I have seen of all kinds do so. However, if your goal is to cause extreme discomfort to your opponents via the use of explicit sexual acts or references in debates, I feel I can be fairly easily persuaded that you can use another method to achieve your goal. The old judging philosophy had a line that "I feel that there are questions better left to outside the competitive debate framework to be resolved." I feel many of these arguments fall into this category.

Risk Analysis: The strength of the link is often the most important factor in evaluating debates to me. I tend to think we overvalue both uniqueness and tend to race toward hyperbolic impacts, causing a decreased emphasis on more tangible, real world concerns. That said, most debaters have given up challenging links and internal links, so I frequently default to the magnitude/time-frame end of the paradigm. When this occurs, the negative wins a tremendous amount of the time.

Last Thoughts: Despite some of the above commentary, I am not nearly as pessimistic about the future of debate as many seem to be. I think the Middle East is a great topic, an area of tremendous concern to the United States, and most debaters work hard and fight hard to create a fair, fun, equitable competitive environment. I look forward to the upcoming season, and if you have any questions feel free to ask. I promise to try hard and to treat you and your arguments with respect. I take my judging obligations very seriously and try my best to follow Scott Harris' rule that because I assume you work hard to be here, I will work hard to judge you. 


\section{APPENDIX IV \\ SAMPLE ELECTRONIC BALLOT}

BallotCode: 608

Round: 7

Room: Business 201

Judge:

Decision - (Enter A for Aff, $\mathrm{N}$ for Neg after the colon) Dec:

Low Point Win? - (Enter Y for Yes, $\mathrm{N}$ for No after the colon) LPW:

Affirmative:

Debater One- (Enter Pts after the colon) A1:

Debater Two - (Enter Pts after the colon) A2:

Negative:

Debater One - (Enter Pts after the colon) N1:

Debater Two - (Enter Pts after the colon) N2:

Enter Comments/Reason for Decision (You can send decision and points immediately and resend with comments later) 


\title{
APPENDIX V
}

\author{
SAMPLE BRIEF
}

\section{They have misidentified what war we're in-flowing their arguments and potentially offering the ballot belies everything they've said about liberal gestures of inclusion-inclusion in debate space is an empty gesture that ensures nothing changes}

Zizek 8 - Institute for Social Sciences, Ljubljana (Slavoj, The Prospects of Radical Politics Today, Int'1 Journal of Baudrillard Studies, 5;1)

Let us take two predominant topics of to day's American radical academia: postcolonial and queer (gay) studies. The problem of postcolonialism is undoubtedly crucial; however, "postcolonial studies" tend to translate it into the multiculturalist problematic of the colonized minorities' "right to narrate" their victimizing experience, of the power mechanisms which repress "otherness," so that, at the end of the day, we learn that the root of postcolonial exploitation is our intolerance toward the Other, and, furthermore, that this intolerance itself is rooted in our intolerance toward the "Stranger in Ourselves," in our inability to confront what we repressed in and of ourselves. The politico-economic struggle is thus imperceptibly transformed into a pseudo-psychoanalytic drama of the subject unable to confront its inner traumas ... The true corruption of American academia is not primarily financial, it is not only that they are able to buy many European critical intellectuals (myself included - up to a point), but conceptual: notions of "European" critical theory are imperceptibly translated into the benign universe of Cultural Studies chic.

My personal experience is that practically all of the "radical" academics silently count on the long-term stability of the American capitalist model, with the secure tenured position as their ultimate professional goal (a surprising number of them even play on the stock market). If there is a thing they are genuinely horrified of, it is a radical shattering of the (relatively) safe life environment of the "symbolic classes" in the developed Western societies. Their excessive Politically Correct zeal when dealing with sexism,

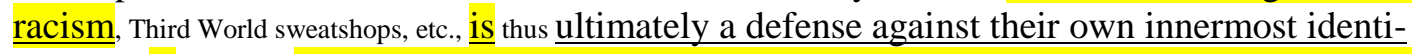
fication, a kind of compulsive ritual whose hidden logic is: "Let's talk as much as possible about the necessity of a radical change to make sure that nothing will really change!" Symptomatic here is the journal October: when you ask one of the editors to what the title refers, they will half-confidentially signal that it is, of course, that October - in this way, one can indulge in the jargonistic analyses of modern art, with the hidden assurance that one is somehow retaining the link with the radical revolutionary past ... With regard to this radical chic, the first gesture toward Third Way ideologists and practitioners should be that of praise: they at least play their game straight and are honest in their acceptance of global capitalist coordinates, in contrast to the pseudo-radical academic Leftists who adopt toward the Third Way the attitude of utter disdain, while their own radicality ultimately amounts to an empty gesture which obligates no one to anything determinate. 


\section{CURRICULUM VITAE}

Tiffany Y. Dillard-Knox

8510 Image Way

Louisville, KY 40299

502-594-1250

Tydill01@1ouisville.edu

\section{Education:}

- $\quad$ Graduate Certificate in Pan-African Studies, 2004

University of Louisville, Louisville, KY

- $\quad$ B.A. Degree in Communication, 2001

University of Louisville, Louisville, KY

\section{Career History and Accomplishments:}

Acting Director of Debate, University of Louisville, 2011-Present

- Named National Female Coach of the Year, 2013

- Named Southeast Regional Director of the Year, 2012

- Coached the program to its first Novice National Championship, 2011

Adjunct Faculty, Department of Communication, Courses Taught, 2004-Present:

- Communication 319, Debate

- Communication 328, Urban Communication

- Communication 111, Speech Communication

Adjunct Faculty, Department of Pan-African Studies, Courses Taught, 2009Present:

- $\quad$ PAS 301, Race and Hip Hop

- PAS 301, Women and Hip Hop

Program Coordinator of Debate, University of Louisville, 2005-2011

- Served on the Executive Council of the Cross Examination Debate Association

- Awarded Regional Graduate Student of the Year

\section{Memberships and Affiliations:}

- Member, Cross Examination Debate Association

- Member, National Debate Tournament 
- Member, National Communication Association

\section{Service:}

- Provides instruction and coaching to high school debaters nationally

- Lab Instructor, University of Louisville's high school debate camp

- Volunteer for the E.S.S.E.N.C.E. Program at the University of Louisville

\section{Publications and Presentations:}

- Panelist, National Communication Association Conference Washington, DC 2013-Mutual Preference Judging in CEDA Debate and Building Coalitions

- Chair and Panel Submitter, National Communication Association Conference San Diego, CA 2008- The State of Interscholastic Debate: A Debate About the Future of Debate (Part 1)

- Panelist, National Communication Association Conference San Antonio, TX 2006- Questioning the Boundaries: Activism, Identity, and Cultural Governance in Debate Practice 